Um sistema de alerta para o monitoramento remoto do consumo de energia usando redes de sensores sem fio

Geraldo Pereira Rocha Filho 



\title{
Um sistema de alerta para o monitoramento remoto do consumo de energia usando redes de sensores sem fio
}

\author{
Geraldo Pereira Rocha Filho
}

Orientador: Prof. Dr. Jó Ueyama

\begin{abstract}
Dissertação apresentada ao Instituto de Ciências Matemáticas e de Computação - ICMC-USP, como parte dos requisitos para obtenção do título de Mestre em Ciências - Ciências de Computação e Matemática Computacional. VERSÃO REVISADA
\end{abstract}


Ficha catalográfica elaborada pela Biblioteca Prof. Achille Bassi e Seção Técnica de Informática, ICMC/USP,

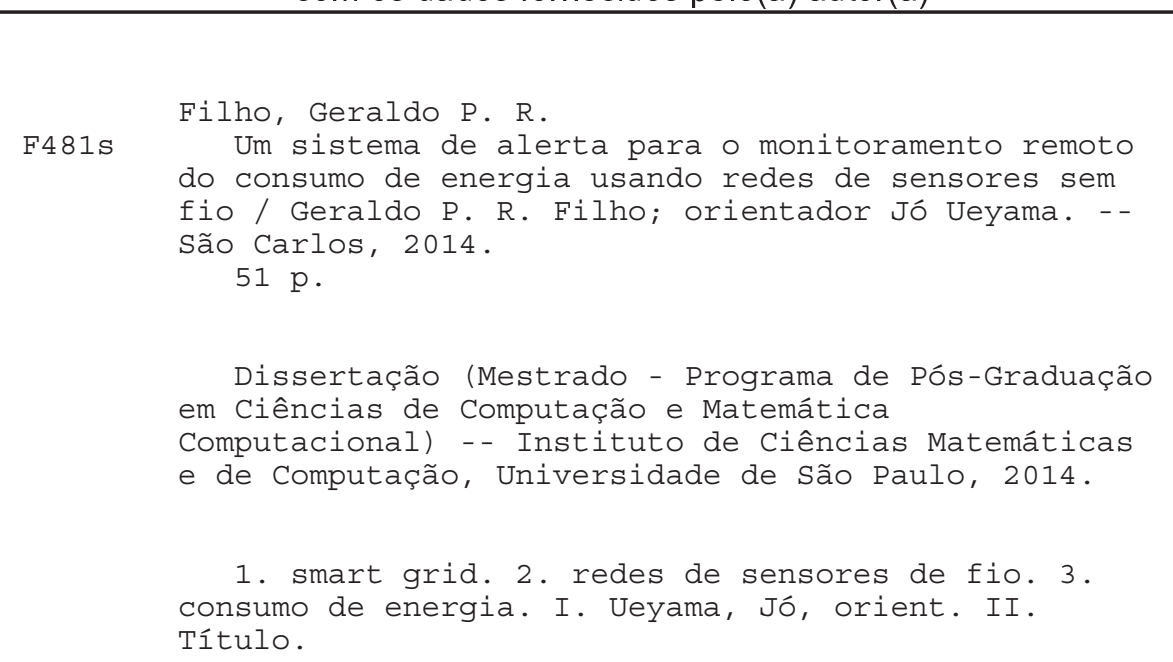


"A mente que se abre a uma nova idéia jamais volta ao seu tamanho original". Albert Einstein 



\section{Agradecimentos}

Primeiramente, agradeço a Deus por ter me guiado para esta tarefa, dando sabedoria e saúde para concluir este trabalho.

Agradeço à minha família, meus pais, Geraldo Pereira Rocha e Adenita Teixeira Pereira, e minha irmã, Thiaquelliny Teixeira Pereira, pelo apoio que sempre ofereceram para mais uma conquista, mostrando desde cedo que com perseverança e dedicação os objetivos almejados são alcançados.

Agradeço ao meu porto seguro, Cristiane de Azevedo, pelo incondicional apoio, bem como suas sábias palavras, encorajando a buscar mais um sonho. Além disso, agradeço a sua compreensão por não estarmos juntos em alguns momentos especiais, para ir em busca desse objetivo.

Agradeço ao meu Orientador, Professor e Auxiliador Jó Ueyama, que além de se tornar um grande amigo, sempre teve paciência e atenção nos momentos em que necessitei de sua ajuda, principalmente nesta etapa final. Ainda, agradeço a sua confiança depositada em mim para a realização desta pesquisa.

Agradeço aos colegas de república Luiz Borro, Alan Valejo e Sérgio Alexandre, que durante a minha estadia em São Carlos se tornaram grandes amigos, além de disponibilizar os seus preciosos tempos por discussões agradáveis.

Agradeço aos amigos Leandro A. Villas, Vinícius Gonçalves, Bruno Faiçal, Gustavo Pessin, Alex A. Pinto, Luiz Nunes, George Gabriel e a todos que colaboraram de forma direta ou indireta para esta pesquisa.

Agradeço ao CAPES (processo DS-7901025/M) e à FAPESP (processo 2012/11206-6) pelo apoio financeiro. 



\section{Resumo}

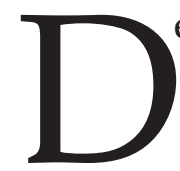

eterminar quais são os equipamentos eletrônicos de uma residência que possuem maior influência na conta de luz não é uma tarefa trivial. As Redes de Sensores Sem Fios (RSSF) auxiliam os usuários nessa tarefa, permitindo descobrir se há algum tipo de desperdício no ambiente monitorado e assim, auxiliá-los a fazer as devidas correções. Por isso, é fundamental usar nas smart grids métodos que detectam novidades, também conhecido como anomalias, de forma individual e autônoma, para os usuários quando algo anômalo surge no consumo de energia dos equipamentos eletrônicos. Tais anomalias podem surgir, por exemplo, quando um equipamento consome energia acima do esperado, o que pode indicar um defeito. Nesse contexto, este trabalho propõe um método inteligente, nomeado como Novelty Detection Power Meter (NodePM), para detectar as novidades no consumo de energia dos equipamento eletrônicos monitorados por uma smart grid. O NodePM detecta as novidades considerando a entropia de cada equipamento monitorado, a qual é calculada com base em um modelo de cadeia de markov que é gerado através de um algoritmo de aprendizado de máquina. Para tanto, o NodePM é integrado a uma plataforma de monitoramento remoto de consumo de energia, que consiste de uma RSSF associada a uma aplicação em nuvem. Para validar o desempenho do NodePM foram feitos experimentos utilizando a análise de variância e testes paramétricos e não-paramétricos. Os resultados de tais experimentos, obtidos mediante a análise estatística, evidenciou a viabilidade do NodePM na plataforma desenvolvida. 



\section{Abstract}

I t is not a simple task to determine which pieces of electronic equipment have the greatest influence on the electricity bill. The Wireless Sensor Networks (WSN) assist users in this task, allowing to discover if there is any type of waste in a monitored environment and thus, help them to take proper actions. Hence, it is of crucial importance to use intelligent methods in the smart grids for novelty detection and to inform the users in an individual and autonomous way when some anomaly has occurred in the energy consumption of electronic equipment. These anomalies can arise, for instance, when a piece of equipment consumes more energy than expected. In this context, we propose an intelligent method, named the Novelty Detection Power Meter (NodePM), to detect the novelties in the energy consumption of electronic equipment monitored by a smart grid. The NodePM detects the novelties considering the entropy of each device monitored, which is calculated based on a Markov chain model that is generated through a machine learning algorithm. For this end, the NodePM is integrated into a platform for the remote monitoring of energy consumption, which consists of a WSN associated with a cloud application. To validate the performance of the NodePM, experiments were done using analysis of variance and parametric and non-parametric tests. The results of these tests, which were obtained from a statistical analysis, provided evidence of the feasibility of the NodePM in the platform that was developed. 



\section{Sumário}

Resumo

Abstract

Lista de figuras $\quad$ viii

Lista de tabelas $\quad$ viii

1 Introdução $\quad 1$

1.1 Contextualização e justificativa . . . . . . . . . . . . . . . . 1

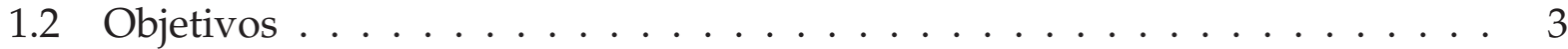

1.3 Estrutura do trabalho . . . . . . . . . . . . . . . . 3

2 Fundamentação teórica $\quad 5$

2.1 Redes de sensores sem fio . . . . . . . . . . . . . . . . . . . . . 5

2.1 .1 Áreas de aplicações das RSSFs . . . . . . . . . . . . . . . . . . 6

2.1.2 Propriedades das RSSFs . . . . . . . . . . . . . . . . 8

2.1 .3 RSSF na smart grid . . . . . . . . . . . . . . . . . . . 10

2.2 Aprendizagem de Máquina . . . . . . . . . . . . . . . . . . 12

2.2.1 Detecção de novidades . . . . . . . . . . . . . . . . . . . . . . 12

2.2 .2 K-Nereast neighbors . . . . . . . . . . . . . . . . 13

2.2 .3 Cadeia de Markov . . . . . . . . . . . . . . . . . . . . 15

2.2.4 Entropia de Shannon . . . . . . . . . . . . . . . . . . . 16

2.3 Trabalhos relacionados . . . . . . . . . . . . . . . . . 17

2.3.1 Trabalhos e iniciativas internacionais . . . . . . . . . . . 18

2.3.2 Trabalhos e iniciativas nacionais . . . . . . . . . . . . . . . . 19

2.3.3 Discussão dos trabalhos relacionados . . . . . . . . . . . . . . . 20

3 Sistema de alerta via RSSF 23

3.1 Sistema de alerta para o monitoramento remoto do consumo de energia . . 23

3.1.1 Plataforma desenvolvida usando RSSF . . . . . . . . . . . . . . . 23

3.1.2 Novelty Detection Power Meter (NodePM) . . . . . . . . . . . . . . . . 27 
4 Experimentos e resultados $\quad 31$

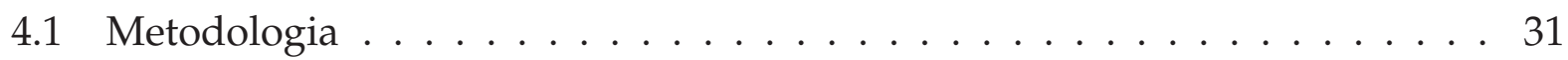

4.1 .1 Base de dados . . . . . . . . . . . . . . . . . . 31

4.1.2 O baseline para o algoritmo proposto . . . . . . . . . . . . . 32

4.1.3 Descrição do ambiente monitorado . . . . . . . . . . . . . . 32

4.2 Experimentos de detecção de novidades com o NodePM . . . . . . . . . . . 33

4.3 Avaliação de desempenho do NodePM com a SONDE . . . . . . . . . . . . . . . . . . . . . . . . . . .

4.3.1 Análise das influências dos parâmetros . . . . . . . . . . . . . . 37

4.3 .2 Discussão dos resultados . . . . . . . . . . . . . . . . 38

4.4 Avaliação de desempenho com o NodePM . . . . . . . . . . . . . . 38

4.4 .1 Discussão dos resultados . . . . . . . . . . . . . . . . . . 41

5 Conclusão $\quad 43$

5.1 Principais contribuições . . . . . . . . . . . . . . . 43

5.2 Produção científica . . . . . . . . . . . . . . . . . . . 44

5.3 Trabalhos futuros . . . . . . . . . . . . . . . . . . 45

$\begin{array}{ll}\text { Referências Bibliográficas } & 51\end{array}$ 


\section{Lista de Figuras}

2.1 Nós sensores espalhados em uma região de interesse com o intuito de sensoriar e enviar informações para uma estação de monitoramento . . . . . . . 5

2.2 Distância Euclidiana entre dois pontos de entradas $u$ e $v$ para um espaço bidimensional . . . . . . . . . . . . . . . . . . . 14

2.3 Diagrama de transição de estado para uma matriz $2 \times 2$, reveja a Matriz 2.716

2.4 Exemplo da Equação 2.9 para o conjunto $P(e)=\{0.1,0.2,0.3, \ldots, 1\} \quad \ldots \ldots 17$

2.5 Exemplo de um sistema após alterar o seu comportamento . . . . . . . . . 17

2.6 Crescimento de publicações na área da smart grid nos últimos 4 anos . . . . 21

3.1 Cenário de funcionamento da plataforma. . . . . . . . . . . . . . . . . 24

3.2 Wattímetro desenvolvido com comunicação sem fio via XBee para a formação da RSSF. . . . . . . . . . . . . . . . . . . . . . . . . . . . . . 25

3.3 Gateway desenvolvido com a plataforma Arduino usando o Shield XBee (Rótulo 1) e o Shield Ethernet (Rótulo 2) . . . . . . . . . . . . . . . . . 26

3.4 Exemplo de classificação do KNN. . . . . . . . . . . . . . . . . . . . . 28

3.5 Matriz de probabilidade e cadeia de Markov a cada instante de tempo de

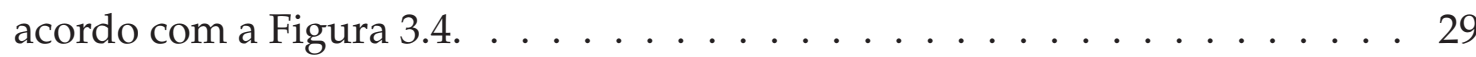

4.1 Detecção de novidades causada pela mudança no comportamento do consumo de energia da geladeira. . . . . . . . . . . . . . . . . . . . 34

4.2 Detecção de novidade com o aumento do consumo inesperado de energia elétrica do roteador. . . . . . . . . . . . . . . . . . . . . . . 35

4.3 Detectando novidade no consumo de energia do tanquinho, o qual possui dados não comportados. . . . . . . . . . . . . . . . . . . . . . . 35

4.4 Medidas de desempenho calculadas a partir da matriz de confusão. . . . . . 36

4.5 Análise de desempenho do NodePM de acordo com a Tabela 4.2. . . . . . . 37

4.6 Usando a plataforma desenvolvida para observar o consumo de energia gasto pelo usuário em um período de 24 horas, identificando equipamentos ociosos, os quais gastam, por exemplo, uma parte considerável do tempo em modo standby. . . . . . . . . . . . . . . . . . . . . . . . . . . 40

4.7 Análise de desempenho do NodePM de acordo com a Tabela 4.4. . . . . . . 40 


\section{Lista de Tabelas}

4.1 Conjunto de equipamentos eletrônicos monitorados através da plataforma desenvolvida(revisite a Seção 3.1) . . . . . . . . . . . . . . . . . . . . 33

4.2 Conjunto de parâmetros escolhidos para serem avaliados . . . . . . . . . . 37

4.3 Influência dos parâmetros em função das medidas de desempenho . . . . . 38

4.4 Conjunto de parâmetros escolhidos para serem avaliados . . . . . . . . . . . 39 


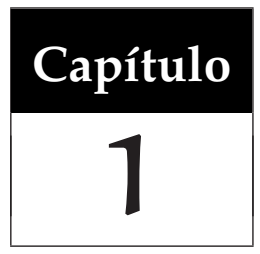

Introdução

\subsection{Contextualização e justificativa}

Nos últimos anos, percebeu-se uma crescente demanda de energia elétrica por parte das indústrias, estabelecimentos comerciais e residências. Essa situação está presente tanto no cenário brasileiro quanto mundial. No período entre 2000 e 2010 o consumo per capta de energia elétrica no Brasil e no mundo aumentou aproximadamente $25 \%$ e $24 \%$, respectivamente (DATA, 2013). Tal cenário, portanto, exige um sistema elétrico mais inteligente que permita reduzir o consumo de energia elétrica em cada equipamento eletrônico, encorajando os consumidores a utilizarem estratégias eficientes para a redução do consumo de energia.

A tecnologia da informação para o sistema elétrico de potência, integrada aos sistemas de comunicação e infraestrutura de rede elétrica, conhecida como smart grid (ENERGY, 2012), permite monitorar e gerenciar o sistema de energia elétrica, em qualquer lugar a qualquer momento. Nesse sentido, a utilização das smart grids tem se tornado cada vez mais importante no cenário urbano, pois oferecem, por exemplo, facilidade de integração em diversas fontes de energia, tais como hidrelétrica, eólica, solar e atômica.

Espera-se que a utilização da smart grid venha a ser uma realidade nos próximos anos, uma vez que as indústrias, universidades e governos do mundo inteiro têm dedicado recursos expressivos para o desenvolvimento dessa tecnologia. Essa tendência pode ser confirmada por meio de diferentes projetos e iniciativas nacionais e internacionais do governo, indústria e academia, dedicados às smart grids (Feisst et al., 2008; Will et al., 2009; Erol-Kantarci \& Mouftah, 2010; AlertMe, 2012; ENERGY, 2012; MAGGI, 2012).

Apesar de todos os avanços conquistados nessa área, tipicamente as concessionárias de energia elétrica fornecem somente o consumo total de energia gasto em uma residência e não oferecem, por exemplo, suporte para gerenciar remotamente o consumo de energia dos equipamentos eletrônicos. Isso significa mais custos para as empresas; além disso, 
determinar quais são os equipamentos eletrônicos que possuem maior influência na conta de luz não é uma tarefa trivial.

Assim, uma alternativa para superar as limitações de serviços oferecidos pelas concessionárias de energia elétrica é integrar uma Rede de Sensores sem Fio (RSSF) nos equipamentos eletrônicos da residência (Botte et al., 2005; Jota et al., 2006; Duarte et al., 2011; Erol-Kantarci \& Mouftah, 2011; Power-Meter, 2012; AlertMe, 2012; Campus-Metabolism, 2012). A partir de uma RSSF é possível estabelecer um sistema que monitora em tempo real o uso de cada tomada de uma residência, permitindo ao usuário conhecer o seu perfil de consumo de energia. A partir disso, o usuário pode descobrir se há algum tipo de desperdício de forma pontual e efetuar as devidas correções. Além disso, com tais informações, por exemplo, é possível oferecer aos usuários o melhor horário de uso de cada equipamento eletrônico mediante tarifas diferenciadas ${ }^{1}$.

Estudos mostram que fornecer informações sobre como, quando, onde e o que os usuários estão usando, os ajuda a tomar decisões corretas (Ester, 1985; Stern, 1999; Mcmakin et al., 2002). É fundamental, portanto, usar nas smart grids métodos inteligentes para detectar novidades, também conhecida como anomalias, de forma individual e autônoma, para os usuários quando algo anômalo surge no consumo de energia dos equipamentos eletrônicos. Tais anomalias podem surgir, por exemplo, quando um equipamento consome energia acima do esperado, o que pode indicar um defeito e/ou quando um equipamento começa a ter um comportamento fora do padrão. Como os padrões comportamentais de cada equipamento eletrônico são diferentes, a identificação de anomalias não é trivial. Por exemplo, o consumo de energia da geladeira é diferente de uma televisão, visto que a primeira permanece ligada constantemente, enquanto que a segunda tem seu uso esporádico.

É fundamental destacar que foram estudados vários trabalhos em relação ao monitoramento do consumo de energia: Botte et al. (2005); Jota et al. (2006); Erol-Kantarci \& Mouftah (2010); Duarte et al. (2011); MAGGI (2012); Power-Meter (2012); CampusMetabolism (2012); AlertMe (2012); SGL (2013); CIB (2013). Entretanto, os trabalhos até o presente momento estudados não concentram esforços para prover uma smart grid integrada com técnicas probabilísticas, tais como Aprendizagem de Máquina (AM), cadeia de Markov e entropia, com o intuito de detectar novidades no consumo de energia dos equipamentos eletrônicos.

Após ter-se delimitado o problema desta pesquisa, faz-se necessário definir o objetivo deste trabalho, conforme está exposto na próxima subseção.

\footnotetext{
${ }^{1}$ É uma modalidade de tarifação que o consumidor pode possuir para reduzir o consumo de energia elétrica fora do horário de pico, similar as tarifas telefônicas.
} 


\subsection{Objetivos}

Como visto anteriormente, a identificação de anomalias no consumo de energia dos equipamentos eletrônicos não é uma tarefa trivial. Nesse sentido, o objetivo deste trabalho é propor um método inteligente, nomeado de Novelty Detection Power Meter (NodePM), para detectar novidades no consumo de energia dos equipamento eletrônicos monitorados por uma smart grid. O NodePM detecta as novidades considerando a entropia do consumo de energia de cada equipamento, a qual é calculada com base em um modelo de cadeia de Markov que é gerado através de um algoritmo de AM, neste caso, o KNereast Neighbors. Para alcançar o objetivo proposto, dados do consumo de energia dos equipamentos eletrônicos foram coletados. Para tanto, desenvolveu-se uma plataforma de monitoramento remoto que consiste de uma RSSF associada a uma aplicação em nuvem. O monitoramento pode ser feito por meio de qualquer dispositivo que tenha acesso à Internet. Consequentemente, é possível enviar alertas autônomos de forma inteligente aos usuários (através de smartphones, por exemplo) quando algo anômalo é identificado no consumo de energia dos equipamentos eletrônicos.

\subsection{Estrutura do trabalho}

O restante deste trabalho está organizado da seguinte forma. No Capítulo 2, é feita uma fundamentação teórica, visando oferecer a base necessária para a compreensão do assunto abordado. No Capítulo 3, é apresentada a proposta desta dissertação, a qual é a contribuição central deste trabalho. No Capítulo 4, são descritos os experimentos realizados e seus resultados são discutidos. Finalmente, o Capítulo 5 apresenta as conclusões deste trabalho, bem como suas contribuições e trabalhos futuros. 



\section{Capítulo}

\section{2}

\section{Fundamentação teórica}

$\mathrm{N}$ este capítulo, é apresentada a fundamentação teórica com a finalidade de fornecer subsídios aos capítulos posteriores. Na Seção 2.1, é realizado um estudo sobre aplicações que utilizam as RSSFs, bem como suas propriedades. Além disso, a viabilidade de integrar sensores sem fios na smart grid é apresentada. Subsequentemente, na Seção 2.2, são apresentados os conceitos para o entendimento do algoritmo proposto. Finalmente, na Seção 2.3, são apresentados e discutidos trabalhos científicos relacionados ao tema desta pesquisa, desde os pioneiros até os mais atuais.

\subsection{Redes de sensores sem fio}

Com base nos autores Akyildiz et al. (2002); Loureiro et al. (2003); Akyildiz \& Vuran (2010); Prathap et al. (2012), uma RSSF pode ser definida como uma rede cooperativa de nós sensores sem fio, cujo principal objetivo é transmitir os dados sensoriados de um ambiente para um nó sorvedouro (conhecido como sink), como ilustrado na Figura 2.1. O nó sink é responsável por receber todos os dados dos nós fontes e enviá-los para um servidor (por exemplo, um servidor em uma nuvem). Os nós fontes são dispersos em uma determinada região, com o intuito de observar um fenômeno de interesse, por exemplo, mudança de temperatura em uma floresta.

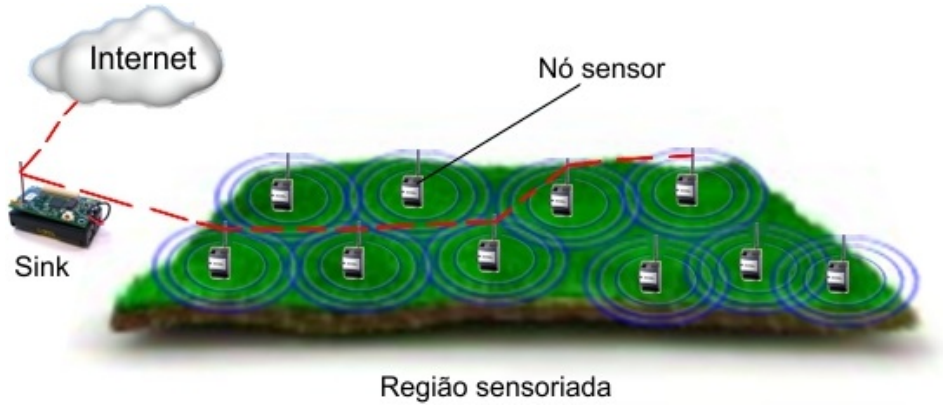

Figura 2.1: Nós sensores espalhados em uma região de interesse com o intuito de sensoriar e enviar informações para uma estação de monitoramento. 
Como dito anteriormente, uma RSSF é composta por uma grande quantidade de nós sensores que são espalhados dentro ou muito próximos ao fenômeno a ser monitorado. Geralmente, cada nó sensor pode ser equipado com vários tipos de sensores, tais como temperatura, pressão e umidade. Esses nós sensores são desenvolvidos para serem de baixo custo e normalmente possuem limitações computacionais, por exemplo, energia, memória e comunicação.

Nos últimos anos, os avanços tecnológicos na área de micro sistemas eletro-mecânicos têm incentivado o desenvolvimento de nós sensores mais robustos (Loureiro et al., 2003; Akyildiz \& Vuran, 2010). Nesse sentido, há uma tendência em produzir sensores menores, mais eficientes, em larga escala, e com baixo custo. Por isso, as RSSFs estão sendo cada vez mais empregadas em diversas áreas da ciência (Sibbald, 2001; Basha et al., 2008; AlertMe, 2012; ENERGY, 2012; Filho et al., 2014).

Na próxima subseção, um estudo sobre aplicações em diversas áreas da ciências (por exemplo, ambientais, médicas e domésticas) que utilizam as RSSFs é apresentado. Em seguida, são apresentadas as propriedades das RSSFs, tais como tarefas típicas e suas características. Finalmente, é apresentado o uso das RSSFs na smart grid, ou seja, na rede de energia elétrica. Como as camadas de protocolos dos nós da rede não estão no escopo deste trabalho, e os seus conceitos não são essenciais para o entendimento desta pesquisa, tais camadas não são apresentadas.

\subsection{1 Áreas de aplicações das RSSFs}

Nesta subseção, é apresentada a utilização das RSSFs nos mais variados lugares, tais como monitoramento de condições ambientais, rastreamento de pessoas, automação de tarefas domésticas e o desenvolvimento de ambientes inteligentes. Tal diversidade está relacionada com os avanços tecnológicos das RSSFs, os quais estimularam o desenvolvimento de inúmeras aplicações possíveis (Sibbald, 2001; Juang et al., 2002; Kim et al., 2008; ErolKantarci \& Mouftah, 2011), incentivando cientistas a desenvolverem pesquisas ostensivas nessa área.

A seguir, algumas aplicações de destaque em RSSFs são descritas e discutidas com base em Rocha (2007) e Akyildiz \& Vuran (2010).

\section{Aplicações ambientais}

A capacidade autônoma da RSSF é usada na execução de uma grande variedade de aplicações ambientais (Juang et al., 2002; Lorincz et al., 2006; Hughes et al., 2011), principalmente por causa da sua flexibilidade de uso. Nesse sentido, usar estruturas da rede cabeada em condições de relevo irregular e vegetação densa nem sempre é possível. Dentre os exemplos de possíveis aplicações ambientais estão: (i) o monitoramento de animais; (ii) o controle de condições ambientais; e (iii) a detecção de inundação.

Monitoração de animais. Uma das aplicações exploradas usando sensores sem fio é o 
monitoramento de animais. O ZebraNet (Juang et al., 2002) é um sistema com essa característica, desenvolvido para analisar os padrões de longo prazo do movimento de zebras, bem como as suas interações entre as espécies, por meio de colares nas zebras. Para tanto, cada colar possui uma unidade de Global Positioning System (GPS), um microcontrolador, dois tipos de rádios (curto alcance e longo alcance), bateria de polímero e um painel solar.

Controle de condições ambientais. Neste seguimento, usando sensores sem fios, é possível monitorar vários fatores ambientais, tais como nível de poluição, umidade e temperatura. Lorincz et al. (2006) demonstram bem o controle de condições ambientais, utilizando uma RSSF para fazer o monitoramento de vulcões. O objetivo da aplicação é coletar dados ao redor dos vulcões, um ambiente inóspito, de acesso inadequado aos seres humanos.

Detecção de inundação. Neste ambiente os sensores são distribuídos ao longo do leito do rio, lago ou córrego, permitindo que as inundações sejam detectadas instantaneamente e com precisão. Hughes et al. (2011) retratam bem esta situação, utilizando as RSSFs para detectar precocemente alertas de inundações no rio Monjolinho na cidade de São Carlos em São Paulo, Brasil. Para tanto, foi implantado um protótipo capaz de coletar informações sobre o nível de água do leito do rio, transmitindo-as a uma estação base. A partir desse ponto, as informações são processadas e alertas podem ser emitidos, caso haja aumento significativo no nível do rio.

\section{Aplicações médicas}

O uso das RSSFs tornou possível integrar sensores inteligentes em dispositivos biomédicos (Sibbald, 2001; Akyildiz et al., 2002; Malan et al., 2004). Por isso, os nós sensores podem ser utilizados em várias vertentes na área da saúde, tais como controle de medicamentos em hospitais; rastreamento de médicos e pacientes; e monitoramento de pacientes.

Controle de medicamentos em hospitais. Neste seguimento, os nós sensores podem ser instalados em medicamentos para prevenir erros de medicação em hospitais, como remédios administrados em hora errada e/ou com doses incorretas, por exemplo. Sibbald (2001) descreve um sistema de monitoramento computadorizado que torna possível reduzir o número de erros relacionados à medicação dos pacientes em hospitais.

Rastreamento de médicos e pacientes. Esse tipo de aplicação proporciona maior facilidade para localizar médicos e pacientes em casos de urgência, por meio de sensores conectados a eles. Akyildiz et al. (2002) destacam o uso desses sensores em hospitais para o rastreamento de médicos. Estes carregam um nó sensor que permite a outros médicos e/ou pacientes serem localizados com agilidade em caso de emergência.

Monitoramento de paciente. São usados em hospitais tanto para monitorar o movimento do paciente quanto para controlar as funções vitais do corpo, por exemplo, batimento cardíaco. Malan et al. (2004) utilizam os sensores para monitorar os sinais vitais do 
paciente em sua rotina. Em seu trabalho os sensores podem, ao mesmo tempo, acompanhar o estado do paciente e/ou fazer a localização do enfermo. Para isso, a equipe médica conta com um Personal Digital Assistants (PDA) para monitorar o paciente, aumentando a chance de sobrevivência do monitorado.

\section{Aplicações domésticas}

Nos últimos anos, percebeu-se que as RSSFs estão sendo cada vez mais usadas em aplicações domésticas (Kim et al., 2008; Erol-Kantarci \& Mouftah, 2011; Filho et al., 2013b). Tal crescimento é relacionado com os avanços tecnológicos nos nós sensores, visto que estes podem ser integrados em equipamentos como geladeira, roteador, microonda e ar condicionado. Uma das vantagens nesse ambiente (Akyildiz \& Vuran, 2010) é a interação que os sensores podem ter uns com os outros para transmitir dados por meio de uma rede externa (Internet) e/ou interna (Intranet). Assim, as RSSFs podem ser utilizadas em diversas funções em aplicações residenciais. A seguir são apresentadas duas dessas funções, sendo elas: (i) a automação de tarefas domésticas; e (ii) o desenvolvimento de ambientes inteligentes.

Automação de tarefas domésticas. Por meio da integração dos sensores sem fio em equipamentos residenciais usados no dia-a-dia, pode-se tornar possível automatizar a maioria das tarefas domésticas, tais como iluminação, controle de equipamentos, monitoramento dos gastos de água e de energia elétrica. $\mathrm{O}$ monitoramento dos gastos de água é destacado por Kim et al. (2008), no qual consiste em um sistema de monitoramento não intrusivo autônomo de água. O objetivo é fornecer aos usuários um sistema fácil de instalar que ofereça informações sobre onde, quando e quanto de água os usuários estão consumindo. Para isso, foram incorporados sensores de vibração sem fio nas tubulações do sistema de encanamento da casa. Dessa forma, não é necessário ter conhecimento especial de canalização para utilizar o sistema.

Ambientes inteligentes. O desenvolvimento de ambientes domésticos inteligentes é um dos principais atrativos das RSSFs, pois dão conforto e segurança para os usuários domésticos, de forma autônoma e inteligente. Erol-Kantarci \& Mouftah (2011) destacam o uso das RSSFs neste tipo de ambiente. Para tanto, os autores propõem com o uso de nós sensores e tarifas diferenciadas, um sistema para a gestão de energia elétrica nos horários de pico.

\subsubsection{Propriedades das RSSFs}

Os ambientes a serem monitorados pelas RSSFs possuem aspectos físicos particulares, tornando assim, a construção da aplicação específica para cada tipo de ambiente. Nesse sentido, esta seção apresenta algumas tarefas típicas que normalmente são encontradas em RSSFs. 


\section{Tarefas típicas das RSSFs}

As atividades requeridas em uma RSSF geralmente dependem do objetivo da aplicação. Tal peculiaridade é relacionada com a tendência que as RSSFs possuem ao executar determinadas tarefas colaborativas. Sendo assim, algumas tarefas que envolvem as RSSFs são apresentadas com base em Loureiro et al. (2003), Rocha (2007) e Akyildiz \& Vuran (2010).

Determinar o valor de algum parâmetro em um dado local. Essa peculiaridade é comum em aplicações ambientais. Por exemplo, deseja-se saber qual é o valor da pressão atmosférica, temperatura e a umidade relativa do ar em locais distintos.

Detectar eventos de interesse e estimar valores em razão do evento detectado. Essa tarefa típica pode ser encontrada em aplicações domésticas. Por exemplo, deseja-se estimar em uma residência quanto o usuário irá gastar de água por mês, sabendo apenas o consumo de água por semana.

Detectar um objeto de interesse. Esse tipo de tarefa pode ser encontrado em aplicação de tráfego. Por exemplo, deseja-se reconhecer determinados veículos (carro, ônibus e/ou caminhões, por exemplo) em uma rodovia.

Rastrear um objeto. Essa peculiaridade também pode ser utilizada em aplicações para monitoramento de animais. Por exemplo, deseja-se saber as rotas de migração das aves.

\section{Características das RSSFs}

As RSSFs possuem características especificas conforme as áreas que são aplicadas. Em razão disso, é necessário tratar questões particulares para que tais características sejam resolvidas. A seguir, algumas características especificas são apresentadas por Correa et al. (2006), Rocha (2007) e Akyildiz \& Vuran (2010).

Endereçamento dos sensores. Dependendo do tipo de aplicação em que a RSSF é usada, o sensor pode ser ou não endereçado individualmente. Quando se deseja conhecer precisamente onde o dado está sendo coletado (por exemplo, monitoramento de sinais vitais do paciente (Malan et al., 2004)), é necessário que os sensores estejam endereçados individualmente. No entanto, se o objetivo da aplicação é saber o valor de uma variável em uma região externa (por exemplo, monitoramento de rio (Hughes et al., 2011)), os sensores não necessitam ser identificados individualmente.

Agregação dos dados. É a capacidade da RSSF de sintetizar os dados coletados pelos sensores. Existem ambientes (por exemplo, rios e florestas), que o sensoriamento pode gerar um elevado nível de transmissão de dados. Caso a rede tenha esse cenário, é possível reduzir os números de mensagens transmitidas pelos sensores. Para tanto, os dados devem ser sintetizados antes de serem transmitidos para uma estação base.

Mobilidade dos sensores. A depender do ambiente em que as RSSFs estão coletando dados, os sensores podem ou não se deslocar. Por exemplo, os sensores são estáticos quando se deseja monitorar o consumo de energia elétrica de uma residência (Duarte et al., 2011; Filho et al., 2013a). Por outro lado, os sensores são móveis quando se deseja, 
por exemplo, rastrear os movimentos de alguma espécie (Juang et al., 2002).

Limitação da energia disponível. Um dos principais fatores limitantes considerado em um sensor e suas aplicações é o consumo de energia. Geralmente, os sensores são colocados em ambientes de difícil acesso, dificultando, assim, a manutenção das aplicações. O tempo de vida útil, neste cenário, é dependente da quantidade de energia que o sensor tem a sua disposição. Dessa forma, para aumentar o tempo de vida dos nós sensores, alguns fatores devem ser levados em considerações, tais como protocolos, algoritmos e tipos de aplicações.

Auto-organização da rede. É a capacidade da rede de configurar os seus recursos (por exemplo, trajetos de comunicação, consumo de energia e posicionamento dos nós) de forma automática e periódica, uma vez que a configuração manual é inviável e muitas vezes impossível. Além disso, sensores podem ficar inativos por causa de problemas de energia e distribuição física. Consequentemente, há a necessidade de mecanismos de auto-organização para que a rede execute suas funções normalmente.

Escalabilidade. A depender do ambiente no qual os nós sensores são utilizados, a rede pode crescer de poucos nós para centenas deles. Por exemplo, o sensoriamento em uma floresta pode precisar de centenas ou até mesmo milhares de nós sensores para monitorar o ambiente.

Tarefas colaborativas. Como dito no início deste capítulo, um dos principais objetivos das RSSFs é executar alguma tarefa colaborativa de interesse. O intuito é detectar, estimar e prover comunicação entre os nós sensores. Por exemplo, instalar nós sensores ao longo do leito de um rio para detectar eventuais inundações em ambientes urbanos.

\subsubsection{RSSF na smart grid}

Segundo Falcão (2009), deve-se entender a smart grid mais como um conceito do que uma tecnologia. Por isso, alguns especialistas definem a smart grid de acordo com a sua concepção (Falcão, 2009; Light, 2012). Nesse sentido, este trabalho, conceitua a smart grid como sendo uma infraestrutura avançada no Sistema Elétrico de Potência (SEP) para melhorar a sua eficiência, confiabilidade e segurança, através de modernas tecnologias de comunicação e de controle automatizado (Siddiqui, 2008; Gungor et al., 2010; Sioshansi, 2012).

Na smart grid (Gungor et al., 2010), informações online e confiáveis são um dos principais fatores para o fornecimento de energia, desde a unidade de geração até a unidade de consumo. Através do monitoramento online é possível, por exemplo, evitar falhas nos equipamentos e/ou prever as limitações do SEP. Nesse sentido, um monitoramento online e, se possível, de baixo custo é essencial para manter a confiabilidade, eficiência e o funcionamento de uma smart grid.

Os recentes avanços na RSSF e sua natureza colaborativa oferecem vantagens expressivas para o SEP, tais como implantação rápida, de baixo custo e flexível (Siddiqui, 2008; 
Falcão, 2009; Gungor et al., 2010). Por isso, as RSSFs têm sido amplamente reconhecidas como uma tecnologia que aprimora vários aspectos do SEP, incluindo os três segmentos que o compõem: (i) geração; (ii) distribuição; e (iii) consumo da energia. O uso da RSSF em uma smart grid permite soluções de forma mais pró-ativa e em tempo oportuno (por exemplo, previsão de falhas nos equipamentos). Nesse sentido, as RSSFs desempenham um papel fundamental no desenvolvimento de uma smart grid de alta confiabilidade, respondendo rapidamente aos eventos online com as ações devidamente apropriadas.

Como dito anteriormente, as RSSFs podem ser aplicadas nos três segmentos do SEP: (i) geração; (ii) distribuição; e (iii) consumo da energia. A seguir, é apresentado o uso das RSSFs em cada segmento do SEP, como descrito por Falcão (2009), Gungor et al. (2010) e Erol-Kantarci \& Mouftah (2011).

Geração. Neste segmento, a rede de energia elétrica tradicional monitora o gerenciamento da energia por meio de sensores com fio. Normalmente, as instalações desses sensores são limitadas e localizadas em locais críticos, tais como oceanos, desertos e montanhas. Além disso, o monitoramento desses ambientes utilizando sensores com fio é inviável e, muitas vezes, impossível devido aos fatores geográficos. Ainda, os sensores com fio são desfavorecidos em relação, por exemplo, a sua manutenção e custosos no que diz respeito a sua instalação. A RSSF veio para tornar esses benefícios viáveis, aprimorando o monitoramento da geração de energia, isto é, na smart grid. Logo, os sensores sem fios estão cada vez mais sendo utilizados, oferecendo uma tecnologia ideal tanto para monitorar quanto para controlar as instalações da geração de energia em ambientes remotos.

Distribuição. Neste segmento, os componentes que precisam ser monitorados em tempo real são, por exemplo, as subestações, redes de energia elétrica e linhas subterrâneas. Qualquer falha em um desses componentes pode ocasionar apagões. Tais falhas costumam ser pontuais e normalmente estão relacionadas com acidentes locais, climáticos e/ou motivos técnicos. A dificuldade do reconhecimento da falha de forma pontual atrasa ainda mais a solução do problema. O uso de uma rede de sensores sem fio oferece soluções promissoras para monitorar e garantir a transmissão e distribuição da energia elétrica de forma eficiente. Isso porque o monitoramento pode ser feito de forma pontual, por meio de vários sensores instalados ao longo da rede elétrica. Dessa forma, os sensores podem executar algumas tarefas colaborativas para estimar e detectar os eventos de interesse.

Consumo. Neste segmento, as instalações da rede de energia elétrica nas casas dos consumidores não são levadas em consideração. Isso torna inviável para os consumidores juntamente com a SEP a buscar formas eficientes de utilizar a energia na sua residência. As smart grids possibilitam isso, permitindo a comunicação entre a concessionária de energia elétrica e as instalações dos consumidores, e vice-versa. Para tanto, é necessário utilizar uma Infraestrutura de Medição Avançada (IMA) e/ou medidores inteligentes. 
Assim, é possível comunicar com os consumidores, monitorar seus aparelhos elétricos e possivelmente controlar seu consumo de energia, sem afetar o seu negócio e/ou conforto. Contudo, os consumidores precisam de ferramentas e tecnologias para fazer a automação de sua casa e, assim, mais uma vez, os sensores sem fios podem ser utilizados para o facilitar o cotidiano do consumidor. Nesse sentido, o uso de sensores sem fios, neste segmento, proporciona varias vantagens, tais como tarifa de energia diferenciada, monitoramento em tempo real dos aparelhos elétricos e transparência no consumo de energia.

\subsection{Aprendizagem de Máquina}

Segundo Mitchell (1997), Aprendizagem de Máquina é uma sub-área da Inteligência Artificial cuja finalidade é desenvolver técnicas que permitam adquirir conhecimento de forma automática em um sistema. Nesse sentido, um sistema de aprendizagem tem o objetivo de tomar decisões baseada em observações que são adquiridas através de experiências acumuladas.

Em termos gerais, há duas categorias de aprendizagem: (i) supervisionada; e (ii) nãosupervisionada. Na aprendizagem supervisionada (Mitchell, 1997; Pratap \& Shelja, 2013), cada valor de entrada requer um valor alvo correspondente que represente o resultado desejado, isto é, a partir de exemplos que estão pré-classificados é possível induzir a classificação de um valor de entrada. Já na aprendizagem não-supervisionada (Mitchell, 1997; Pratap \& Shelja, 2013), cada valor de entrada não requer um valor alvo correspondente, ou seja, não é necessário fornecer nenhum exemplo pré-classificado para induzir o valor de entrada para um grupo. Para tanto, utiliza-se métodos probabilísticos (por exemplo, aprendizagem bayesiana) para descobrir padrões nos dados de entradas.

Nos últimos anos, as técnicas de AM têm sido usadas em vários problemas reais envolvendo a análise automática dos dados (Spinosa, 2008). Tal cenário é presente neste trabalho, uma vez que os conceitos de AM são empregados para agrupar os dados descentralizados recebidos das RSSFs.

De acordo com as áreas que os diversos sistemas são aplicados tanto as técnicas de AM quanto o ambiente monitorado pela RSSF possuem características particulares. Assim, a seguir, são apresentados os conceitos básicos para obter o agrupamento dos dados recebidos da RSSF.

\subsubsection{Detecção de novidades}

Segundo Spinosa (2008), o termo detecção de novidade pode ser usado para fazer referência a abordagens que são fundamentalmente distintas, dependendo, entre outros aspectos, da aplicação em que o trabalho se insere. No contexto desta pesquisa, o termo detecção de novidade está relacionado com a capacidade que o sistema possui de identificar anomalias, no consumo de energia dos equipamentos eletrônicos, à medida que os dados da RSSF são recebidos. 
É fundamental, portanto, conhecer a distribuição dos dados para a detecção de novidades. Para tanto, técnicas não-paramétricas são usadas para tal propósito, as quais consideram exemplos do conjunto de treinamento para estimar o seu grupo. Uma das técnicas que têm sido utilizadas para detectar novidades em aplicações reais (por exemplo, identificação de veículos em imagens (Munroe \& Madden, 2005) e detecção de falhas em motores (Casimir et al., 2006)), é o k-nereast neighbors.

\subsubsection{K-Nereast neighbors}

O K-Nearest Neighbors (KNN) (Cover \& Hart, 1967) é um método de classificação nãoparamétrico e supervisionado. Uma das características principais do algoritmo é utilizar exemplos de treinamento para realizar predições ou classificações sem manter um modelo de classificação derivado dos dados (Cover \& Hart, 1967). Assim, o algoritmo utiliza as observações do conjunto de treino, as similaridades dos vizinhos e os valores de saídas para classificar ou predizer uma determinada informação. Por exemplo, é possível classificar o estado de um equipamento eletrônico, tais como standby ou ligado/desligado, com base na sua Potência (Watt) e Tempo de uso (Minuto).

No Algoritmo 2.1, é apresentado o funcionamento do KNN. O KNN é composto basicamente por três fases. Na primeira fase, deve-se armazenar o conjunto de treinamento (veja os "Dados" do Algoritmo 2.1). Na segunda fase, deve-se calcular para uma nova instância a sua similaridade em relação ao conjunto de treinamento (linhas 2 a 5 do Algoritmo 2.1). Por fim, na terceira fase, a nova instância é classificada mediante a classe mais frequente (linhas 6 a 8 do Algoritmo 2.1). Como o KNN não possui processamento na fase de treinamento (primeira fase), a classificação de uma determinada instância se torna rápida (Mitchell, 1997).

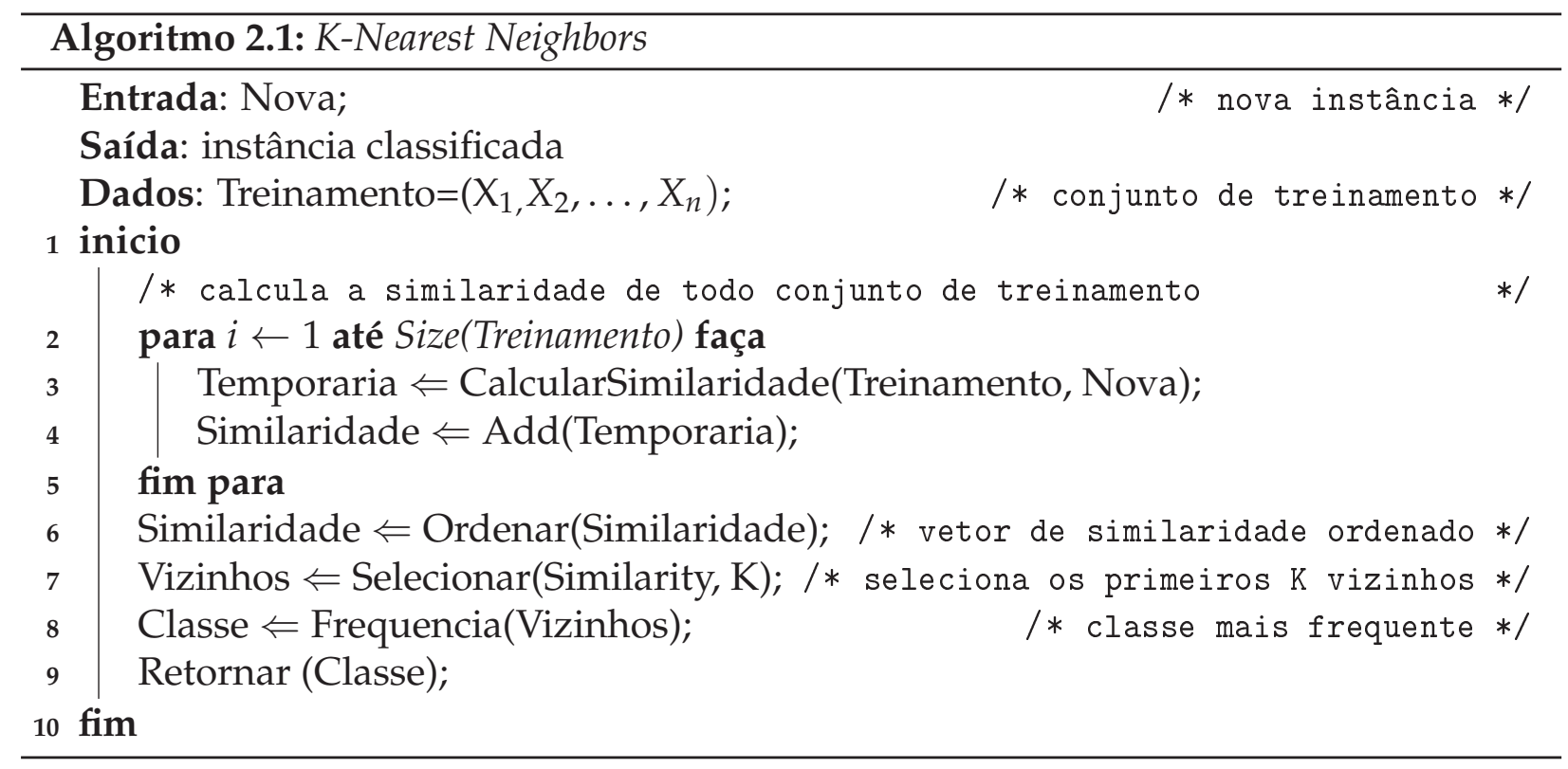

Como cada instância do KNN pode ser representada por um ponto no espaço, é pos- 
sível quantificar a similaridade entre duas instâncias através da distância (Cover \& Hart, 1967). Para tanto, é necessário definir funções de distância para mensurar a similaridade. Segundo Larose (2005), a função de distância é uma função real $d$ que deve satisfazer as seguintes propriedades para qualquer coordenada $x, y$ e $z$ :

$$
\left\{\begin{array}{l}
d(x, y) \geq 0, d(x, y)=0 \Leftrightarrow x=y \\
d(x, y)=d(y, x) \\
d(x, z) \leq d(x, y)+d(y, z)
\end{array}\right.
$$

A Propriedade 2.1 garante que a distância é sempre positiva, e a única maneira da distância ser zero é quando as coordenadas estão no mesmo ponto. A Propriedade 2.2 garante a comutatividade, isto é, a distância de $x$ para $y$ é a mesma que a distância de $y$ para $x$. Finalmente, a Propriedade 2.3 garante a desigualdade triangular, ou seja, a introdução de um terceiro ponto $y$ não encurta a distância entre dois outros pontos $x$ e $z$.

Para calcular a similaridade entre as instâncias, a função mais usada é a Euclidiana (Larose, 2005). Assim, a distância entre os pontos $u=\left(u_{1}, u_{2}, \ldots, u_{n}\right)$ e $v=\left(v_{1}, v_{2}, \ldots, v_{n}\right)$ em um espaço de $n$-dimensões é calculada de acordo com a Equação 2.4 .

$$
d(u, v)=\sqrt{\left(u_{1}-v_{1}\right)^{2}+\left(u_{2}-v_{2}\right)^{2}+\cdots+\left(u_{p}-v_{p}\right)^{2}}
$$

Como exemplo da função Euclidiana, a Figura 2.2 ilustra um espaço bidimensional com dois pontos de entradas $u=(u 1, u 2)$ e $v=(v 1, v 2)$. Os pontos são representados pelos rótulos 1 e 2 da Figura 2.2. Assim, a distância $d$ entre os dois pontos é computada com a raiz quadrada da soma de $d u$ e $d v$ ao quadrado (rótulo 3 da Figura 2.2).

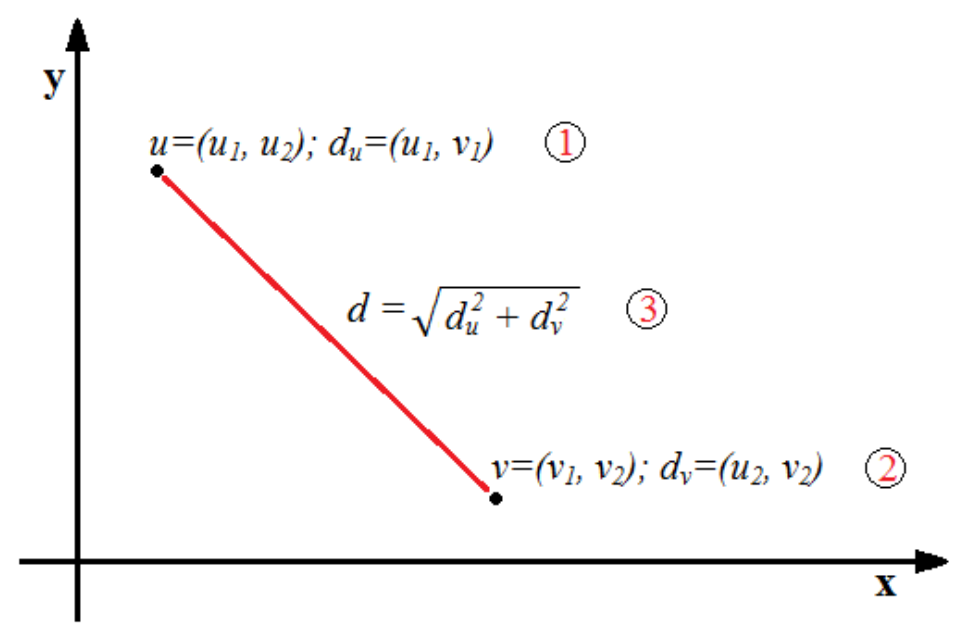

Figura 2.2: Distância Euclidiana entre dois pontos de entradas $u$ e $v$ para um espaço bidimensional. 


\subsubsection{Cadeia de Markov}

De acordo com Ross (1997), um processo estocástico é definido como uma coleção de variáveis aleatórias $\left\{X_{t}, t \in T\right\}$, isto é, $X_{t}$ possui um parâmetro $t$ pertencente a um conjunto $T$. A menos que indicado de outra forma, o conjunto $T$ será denotado pelo conjunto dos números inteiros não negativos $\left\{T \subset Z^{+}\right\}$. Assume-se tipicamente o conjunto $T$ como tempo e $X_{t}$ como o estado do processo no instante $t$.

Segundo Ross (1997), ao considerar um processo estocástico como $\left\{X_{t}, t=0,1,2 \ldots\right\}$ que pode assumir um número finito de possíveis valores, diz que $X_{t}=i$ é um processo que está no estado $i$ no instante $t$. Assim, uma cadeia de Markov (Markov, 1971) é um processo estocástico definido como:

$$
P\left\{X_{t+1}=j \mid X_{t}=i, X_{t-1}=i_{t-1}, \ldots, X_{1}=i_{1}, X_{0}=i_{0}\right\}=P_{i j}
$$

Para todos os estados $i_{0}, i_{1}, \ldots, i_{t-1}, i, j$ e todo $t \geq 0$. O $P_{i j}$ é a probabilidade de transição do processo ir do estado $i$ para o estado $j$, com uma probabilidade fixa. Dessa forma, para uma cadeia de Markov (revisite a equação 2.5) a distribuição condicionada de qualquer estado futuro $X_{t+1}$, dados os estados passados $X_{0}, X_{1}, \ldots, X_{t-1}$ e o estado presente $X_{t}$, é independente dos estados passados e depende apenas do estado presente (Markov, 1971; Ross, 1997). Isto é, um processo estocástico é um processo Markoviano se o estado futuro depende unicamente do estado presente, sendo o estado passado irrelevante. Este tipo de processo estocástico é caracterizado sem memória e, por isso, tais processos possuem grande aplicabilidade no mundo real (Markov, 1971).

Como as probabilidades são não negativas e o processo deve realizar uma transição para um estado, tem-se (Ross, 1997):

$$
P_{i j} \geq 0, i, j \geq 0 ; \sum_{j=0}^{\infty} P_{i j}=1, i=0,1, \ldots
$$

Com isso, obtém-se a matriz de transição de estados $P$, como ilustrado na Matriz 2.7.

$$
P=\left|\begin{array}{ccccc}
P_{00} & P_{01} & P_{02} & \cdots & P_{0 j} \\
P_{10} & P_{11} & P_{12} & \cdots & P_{1 j} \\
\vdots & \vdots & \vdots & \ddots & \vdots \\
P_{i 0} & P_{i 1} & P_{i 2} & \cdots & P_{i j}
\end{array}\right|
$$

A Figura 2.3 apresenta um diagrama de transição de estado, uma alternativa para representar as probabilidades de transição de uma matriz. Na Figura 2.3, os círculos representam os estados e as arestas representam as transições entre os estados com as suas respectivas probabilidades. 


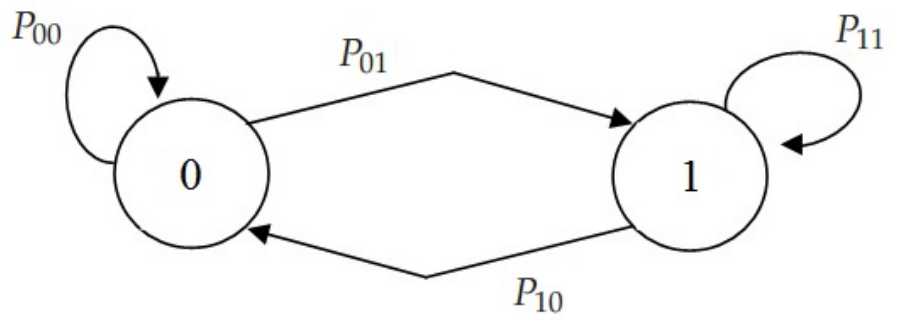

Figura 2.3: Diagrama de transição de estado para uma matriz $2 \times 2$, reveja a Matriz 2.7.

No contexto desta pesquisa, as cadeias de Markov são utilizadas para agrupar os dados descentralizados da RSSF. Com isto, é possível representar as relações entre os diferentes estados que um processo compõe. Isto é, capturar a dinâmica comportamental de um processo, neste caso, equipamentos eletrônicos.

\subsubsection{Entropia de Shannon}

Nesta seção, são apresentados os fundamentos da entropia de Shannon, bem como o seu uso na cadeia de Markov. O intuito é apresentar como a entropia pode ser usada para a detecção de novidades.

De acordo com a teoria da informação de Shannon (Shannon, 1948), pode-se entender a entropia como uma medida de incerteza, e/ou ganho de informação, em um dado sistema com base em uma probabilidade de um determinado evento ocorrer. De maneira formal, tem-se:

$$
E(i)=-\sum_{i=1}^{q} P\left(s_{i}\right) \log _{2}\left(P\left(s_{i}\right)\right)
$$

Onde $q$ é a quantidade de eventos; $P\left(s_{i}\right)$ é a probabilidade de um evento ir para um outro estado; e $E(I)$ é o grau de incerteza (entropia) de uma distribuição. É fundamental destacar que o $\log _{2}$ é usado para quantificar a entropia em termos de bits. De acordo com Freeman \& Skapura (1991), pode-se definir um bit como a quantidade de informação recebida quando uma das duas alternativas igualmente prováveis é especificada. Formalmente tem-se:

$$
I(e)=\log _{2} \frac{1}{P(e)}
$$

Com base na Equação 2.9, a Figura 2.4 representa bem essa situação. Para tanto, considere o conjunto $P(e)=\{0.1,0.2,0.3, \ldots, 1\}$, onde $e$ é um evento e $P(e)$ é a probabilidade com que esse evento pode ocorrer. Nesse sentido, quando tem-se a certeza que um evento irá ocorrer, $P(1)$, a sua ocorrencia não traz nehuma informação: $I(e)=\log _{2}\left(\frac{1}{1}\right)$, rótulo 1 da Figura 2.4. No entanto, quanto menos certeza se tem sobre a ocorrencia de um evento, por exemplo, $P(0.1)$, maior é a quantidade de informação recebida, rótulo 2 da Figura 2.4. 


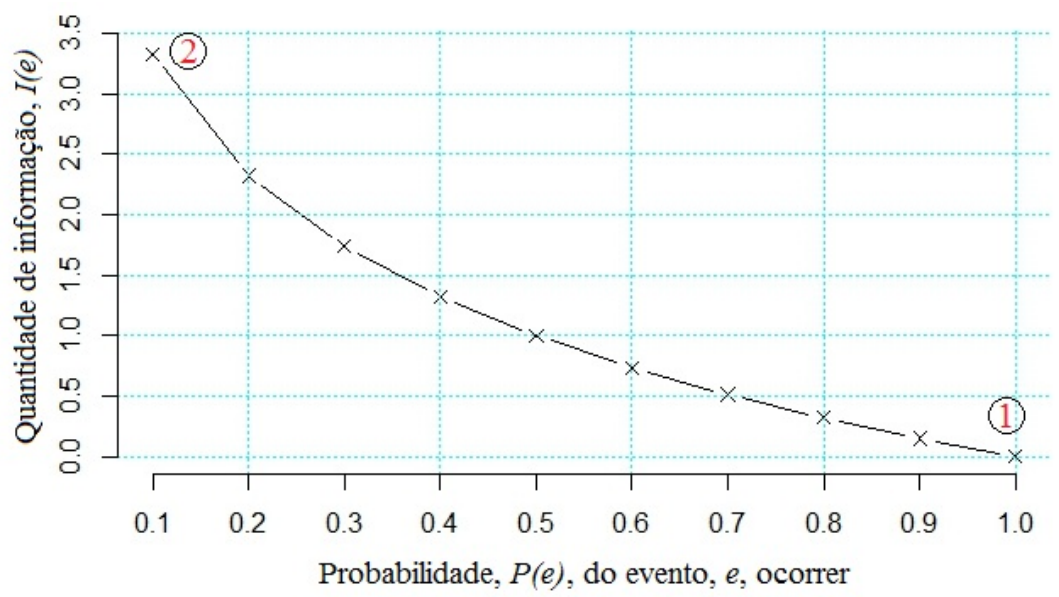

Figura 2.4: Exemplo da Equação 2.9 para o conjunto $P(e)=\{0.1,0.2,0.3, \ldots, 1\}$.

Para entender como a entropia pode ser utilizada na detecção de novidades, considere o sistema da Figura 2.5a, reveja o diagrama de transição da cadeia de Markov da Figura 2.3. Nesta situação, mediante a equação 2.8 , tem-se: $E=-\left(1 \log _{2}(1)+1 \log _{2}(1)\right)=0$. Isto é, nenhum nível de incerteza/entropia foi agregado. Em outra situação, considere que o sistema alterou o seu comportamento, como ilustrado na Figura 2.5b. Neste caso, tem-se: $E=-\left(1 \log _{2}(1)+0.5 \log _{2}(0.5)+0.5 \log _{2}(0.5)\right)=1$. Ou seja, o sistema agregou maior nível de incerteza/entropia.

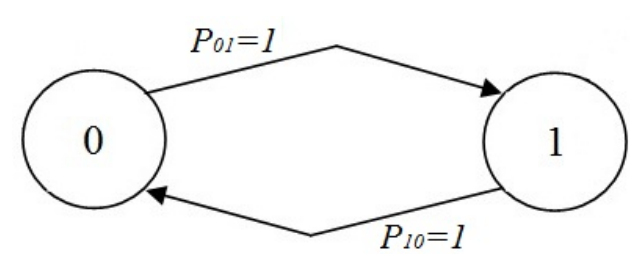

(a) Comportamento de um sistema sem nenhum nível de entropia.

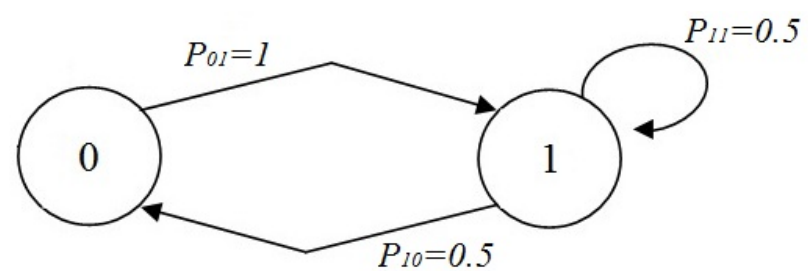

(b) Comportamento de um sistema com aumento no nível de entropia.

Figura 2.5: Exemplo de um sistema após alterar o seu comportamento.

Nesse sentido, o nível de incerteza das cadeias de Markov pode ser obtida por meio da entropia. Isto é, quando houver alterações nas probabilidades da cadeia de Markov, utiliza-se a equação 2.8 como uma medida de incerteza. Logo, detecta-se que o sistema divergiu do esperado, ou seja, ocorreu uma novidade, quando há uma variação significativa na entropia.

\subsection{Trabalhos relacionados}

Atualmente, diferentes projetos de pesquisa tanto internacionais quanto nacionais têm sido publicados ao longo dos anos na área da smart grid (Botte et al., 2005; Jota et al., 2006; Erol-Kantarci \& Mouftah, 2010; Duarte et al., 2011; MAGGI, 2012; Power-Meter, 2012; 
Campus-Metabolism, 2012; AlertMe, 2012; SGL, 2013; CIB, 2013). Tais trabalhos apresentam importantes desafios e propostas nessa área, que vão desde a regulamentação (MAGGI, 2012) até a implantação (SGL, 2013; CIB, 2013). Nesse sentido, tem-se buscado diferentes soluções para os mais diversos problemas na área da smart grid (Botte et al., 2005; Jota et al., 2006; Erol-Kantarci \& Mouftah, 2010; Duarte et al., 2011). No entanto, apesar de todos os recentes avanços conquistados, ainda há vários desafios e problemas em aberto nessa área. Por exemplo, a inexistência de uma metodologia para detectar anomalias/novidades no consumo de energia dos equipamentos eletrônicos monitorados por uma smart grid. Sendo assim, a seguir são apresentados alguns trabalhos científicos cujo foco corresponde, principalmente, ao monitoramento do consumo de energia elétrica. Em seguida, uma discussão dos trabalhos relacionados é apresentada.

\subsubsection{Trabalhos e iniciativas internacionais}

Um dos modelos mais antigo de uma smart grid é o projeto Telegestore (Botte et al., 2005). O Telegestore é um sistema que gerencia os medidores residenciais e comerciais remotamente, visando explorar a rede de distribuição de baixa tensão entre os transformadores e os medidores. O projeto consiste de três componentes chaves que são: (i) o medidor eletrônico que coleta informações do ambiente monitorado; (ii) o concentrador o qual é instalado próximos dos transformadores, coletando os dados registrados pelos medidores; e (iii) o sistema central para o gerenciamento remoto dos medidores, processando informações de faturamento e monitorando a qualidade do serviço. Com essa infraestrutura de gerenciamento, a comunicação dos medidores eletrônicos além de ser bidirecional, se dá de forma automática a qualquer momento. Dessa forma, é possível ler o consumo de energia gasto pelos usuários e administrar operações contratuais dos mesmos remotamente.

Com essa infraestrutura de gerenciamento, a comunicação dos medidores eletrônicos além de ser bidirecional, se dar de forma automática a qualquer momento. Dessa forma, é possível ler o consumo de energia gasto pelos usuários e administrar operações contratuais dos mesmos remotamente.

Erol-Kantarci \& Mouftah (2010) propõem um trabalho nomeado Appliance Coordination (ACORD) para reduzir o custo de energia nas horas de pico. Para tanto, uma RSSF é utilizada para comunicar com a Unidade de Gestão de Energia (UGE). A UGE coordena o uso dos equipamentos eletrônicos solicitado pelo usuário de acordo com as taxas de tempo de uso, as quais diferem dependendo do horário. Dessa forma, a UGE agenda as solicitações dos usuários, evitando utilizar os equipamentos nas horas em que a taxa de uso é maior. Consequentemente, os usuários se beneficiam mediante o faturamento da sua conta de energia.

O projeto Campus Metabolism (CM) (Campus-Metabolism, 2012), gerenciado pela Arizona State University (ASU), é uma ferramenta web que monitora o uso dos recursos da 
energia elétrica em tempo real nos edifícios da ASU, agrupando os dados em três categorias: (i) eletricidade ${ }^{1}$; (ii) aquecimento ${ }^{2}$; e (iii) refrigeração ${ }^{3}$. Através de uma rede dedicada de fibra ótica, os dados são coletados e armazenados em uma base de dados. Assim, as informações dos recursos consumidos são disponibilizadas mediante um sistema web, o qual é gerenciado pela própria ASU. Além disso, o CM faz parte do projeto CarbonPlan, o qual tem a meta de possuir carbono neutro até o ano de 2025.

Existem também iniciativas de empresas que buscam monitorar o consumo de energia elétrica, como o feito pelo AlertMe (AlertMe, 2012). Este já conquistou 13 prêmios ${ }^{4}$ de inovação de produtos e estratégia de negócios. O principal objetivo do AlertMe é auxiliar o usuário a monitorar e administrar o consumo de energia elétrica, por exemplo, em uma residência. Para tanto, medidores sem fios (conhecido como SmartPlug) são utilizados para mensurar o consumo de energia. Os SmartPlugs utilizam o protocolo de comunicação sem fio (ZigBee) para enviar as informações de consumo para um SmartHub, que por sua vez, transmite tais informações para um sistema baseado em nuvem do AlertMe. Além disso, o AlertMe utiliza o monitoramento de carga não intrusiva para, por exemplo, detectar quais aparelhos estão sendo usados mediante variação de tensão e corrente.

\subsubsection{Trabalhos e iniciativas nacionais}

No Brasil, também há iniciativas em relação às smart grids, como o Centro de Monitoramento de Usos Finais (CMUF) (Jota et al., 2006). O projeto CMUF objetiva ajudar as pessoas a monitorar o consumo de energia elétrica em tempo real, consistindo de um sistema de baixo custo. Além disso, o seu monitoramento pode ser feito por setores, ou seja, fazendo medições do consumo de uma forma geral, do consumo por andar ou até mesmo por uma determinada área, isoladamente. Para tanto, a comunicação entre as estações de medição e controle são interligadas por meio de uma rede de área controlada, isto é, controller area network ${ }^{5}$. Dessa forma, a conexão com a Internet se dá através de um webserver. Assim, as informações coletadas são enviadas para o banco de dados do CMUF. Logo, os dados ficam disponibilizados para usuários cadastrados via um website.

Duarte et al. (2011) propõem a concepção, o desenvolvimento e a implementação de uma rede de sensores para fazer a medição da energia elétrica em uma residência. Para tanto, três módulos de medição (smart meters) são propostos para monitorar o consumo de energia de cada dispositivo eletrônico, tais como televisão, chuveiro elétrico e lâmpada. Os três smart meters propostos são: (i) para dispositivos que podem ser conectados na tomada com baixa carga, por exemplo, televisão; (ii) para dispositivos que são conectados na tomada com alta carga, por exemplo, chuveiro elétrico; e (iii) para equipamentos

\footnotetext{
${ }^{1}$ Usado para o consumo de energia elétrica das luzes e dos equipamentos eletrônicos.

${ }^{2}$ Usado para aquecer a água e o ar do ambiente.

${ }^{3}$ Usado para resfriar a água e ar do ambiente.

${ }^{4}$ Awards and Recognition, https: / / www.alertme.com/about-us / our-awards

${ }^{5}$ Protocolo de comunicação serial utilizado em aplicações de tempo real.
} 
que emitem luz, os quais não podem ser conectados em uma tomada, tais como lâmpadas e/ou abajures. Assim, cada um dos smart meters mede o consumo de forma diferenciada. Além disso, a comunicação é via ZigBee e os medidores podem ser utilizados simultaneamente.

No Rio de Janeiro, a concessionária de energia elétrica Light possui um programa nomeado de Smart Grid Light (SGL, 2013). Um dos objetivos do programa é acompanhar o consumo de energia elétrica dos consumidores em tempo real. Para tanto, medidores inteligentes com certificação digital são utilizados. Os medidores são de dois tipos: medidor inteligente com mostrador embutido e medidor inteligente com mostrador remoto. $\mathrm{O}$ primeiro é instalado no local do medidor tradicional. Já o segundo, fica fora da residência, por exemplo, instalado no poste. Caso o segundo seja utilizado, um visor é conectado em uma tomada dentro da residência, mostrando, por exemplo, o consumo atual de energia e/ou sua estimativa. Portanto, é possível estimar e configurar metas com o intuito de evitar os horários de pico (caso tarifas diferenciadas por horário de consumo sejam empregadas, por exemplo, como acontece na conta de telefone/celular) e detectar pontos de desperdícios no consumo de energia.

Outro projeto do estado do Rio de Janeiro gerenciado pela empresa Ampla em Búzios, nomeado Cidade Inteligente (CIB, 2013), também apresenta iniciativas relacionadas às smart grids. O intuito do projeto é implantar uma infraestrutura de rede elétrica inteligente na cidade de Búzios para racionalizar o consumo de energia. Para tanto, o projeto planeja modernizar a iluminação pública, os prédios, as casas e estabelecer a tarifa diferenciada, por exemplo. Ainda, o projeto pretende implantar a geração inteligente de energia.

\subsubsection{Discussão dos trabalhos relacionados}

Como visto anteriormente, os trabalhos apresentados possuem contribuições reais para a sociedade, empresa e o meio acadêmico. Outro fator a ser analisado são as diversas abordagens propostas em relação às smart grids (por exemplo, diferentes modelos para monitorar o consumo de energia, propostas de tarifas diferenciadas e monitoramento em tempo real via website). Além disso, nota-se que há uma ascensão para publicações na área da smart grid, como apresentado na Figura 2.6. Para tanto, utilizou-se a base de dados do Scopus ${ }^{6}$ e da IEEE ${ }^{7}$, com a palavra chave: smart grid.

É fundamental destacar que embora as soluções propostas para gerenciar o consumo de energia elétrica se mostrem eficientes, as mesmas não concentram esforços para prover uma smart grid integrada com técnicas probabilísticas (por exemplo, AM, cadeia de Markov e entropia). Nesse sentido, esta pesquisa diferencia-se das soluções existentes em pelo menos três aspectos: (i) utiliza uma RSSF para sensoriar os dados dos equipamentos

\footnotetext{
${ }^{6}$ Scopus, http://www.scopus.com

${ }^{7}$ IEEE Xplore, http:/ / ieeexplore.ieee.org
} 


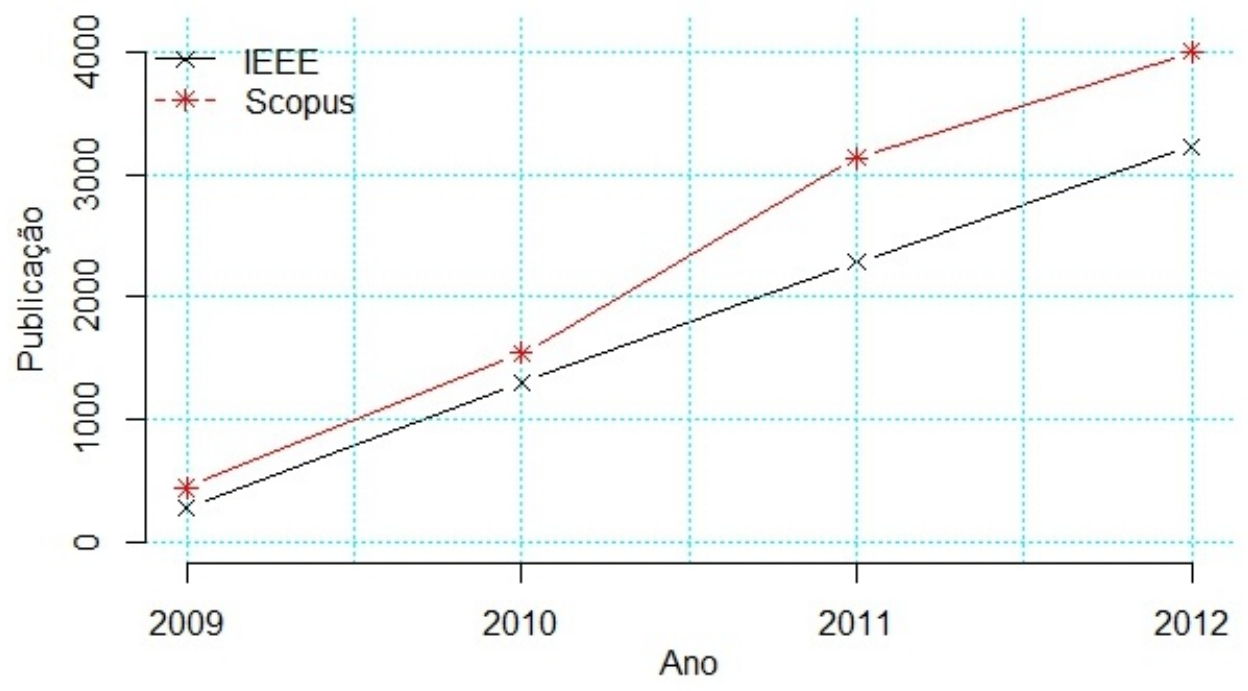

Figura 2.6: Crescimento de publicações na área da smart grid nos últimos 4 anos.

eletrônicos; (ii) desenvolve um protótipo para coletar dados da RSSF; e (iii) propõe um algoritmo para detectar novidades nos equipamentos eletrônicos baseado em técnicas probabilísticas. Ainda, é possível analisar o comportamento dos equipamentos eletrônicos e dos usuários, caso necessário, mediante as probabilidades das cadeias de Markov. 



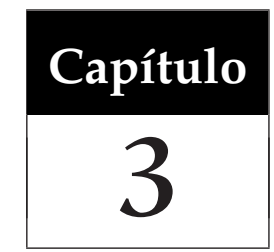

\section{Sistema de alerta via RSSF}

$\mathrm{N}$ este capítulo, é apresentado o objetivo deste trabalho, isto é, a proposta do Novelty Detection Power Meter (NodePM) que é baseado em técnicas probabilísticas, tais como AM, cadeia de Markov e entropia. Além disso, o desenvolvimento da plataforma de monitoramento remoto do consumo de energia para os equipamentos eletrônicos é apresentado.

\subsection{Sistema de alerta para o monitoramento remoto do consumo de ener-} gia

Com a finalidade de alcançar os objetivos deste trabalho, algumas etapas foram necessárias, sendo as principais: (i) o desenvolvimento de uma plataforma na qual utiliza uma RSSF associada a uma aplicação em nuvem; e (ii) a proposta do NodePM para detectar novidades no consumo de energia dos equipamentos eletrônicos. É fundamental destacar que as novidades podem surgir, por exemplo, quando um equipamento consome energia acima do esperado e/ou quando o equipamento começa a ter um comportamento fora do padrão.

Deve-se ressaltar, portanto, que a plataforma desenvolvida é de simples instalação e fácil utilização, assim não é necessário ter um especialista na área. O NodePM é integrado na plataforma a fim de detectar novidades no ambiente monitorado. Além disso, o sistema desenvolvido permite monitorar o consumo de energia elétrica em qualquer lugar, a qualquer momento. A seguir são apresentados o funcionamento da plataforma (Subseção 3.1.1) e a proposta do NodePM (Subseção 3.1.2).

\subsubsection{Plataforma desenvolvida usando RSSF}

A plataforma proposta (Figura 3.1) é composta por três etapas:

- A Etapa 1 é responsável pela aquisição dos dados de consumo dos equipamentos eletrônicos por meio de uma RSSF. 
- A Etapa 2 está relacionada com o processamento dos dados coletados na Etapa 1. Para tanto, foi desenvolvido um gateway e uma aplicação em um servidor em nuvem (app engine ${ }^{1}$ ), no qual gerencia os dados recebidos da RSSF.

- Finalmente, a Etapa 3 é responsável pela disponibilização das informações sobre o consumo de energia elétrica para os interessados. Para isso, um protótipo para smartphone foi desenvolvido.

Na Figura 3.1, é apresentado o funcionamento da plataforma de monitoramento remoto do consumo de energia elétrica. Para isso, foram construídos protótipos de RSSF a partir da montagem de wattímetros (equipamentos que medem o consumo de energia elétrica) Kill-a-Watt da empresa $\mathrm{P}^{2}{ }^{2}$. Os wattímetros são ligados diretamente em uma tomada e junto a ela é conectado o equipamento que deseja monitorar (Rótulo 1, Figura 3.1). Como os wattímetros não possuem acesso a nenhum meio de comunicação, foi adicionado a eles um módulo $\mathrm{XBee}^{3}$ com vistas a transmitir as informações de consumo de energia para um servidor. Dessa forma, construiu-se uma infraestrutura, gateway Arduino ${ }^{4}$, (Rótulo 2, Figura 3.1) para enviar as informações usando a tecnologia de rede sem fio presente nas RSSFs; e transmitir os dados lidos para o servidor em nuvem (Rótulo 3, Figura 3.1), onde é implementado o NodePM (descrito na Subseção 3.1.2). O servidor recebe os da-

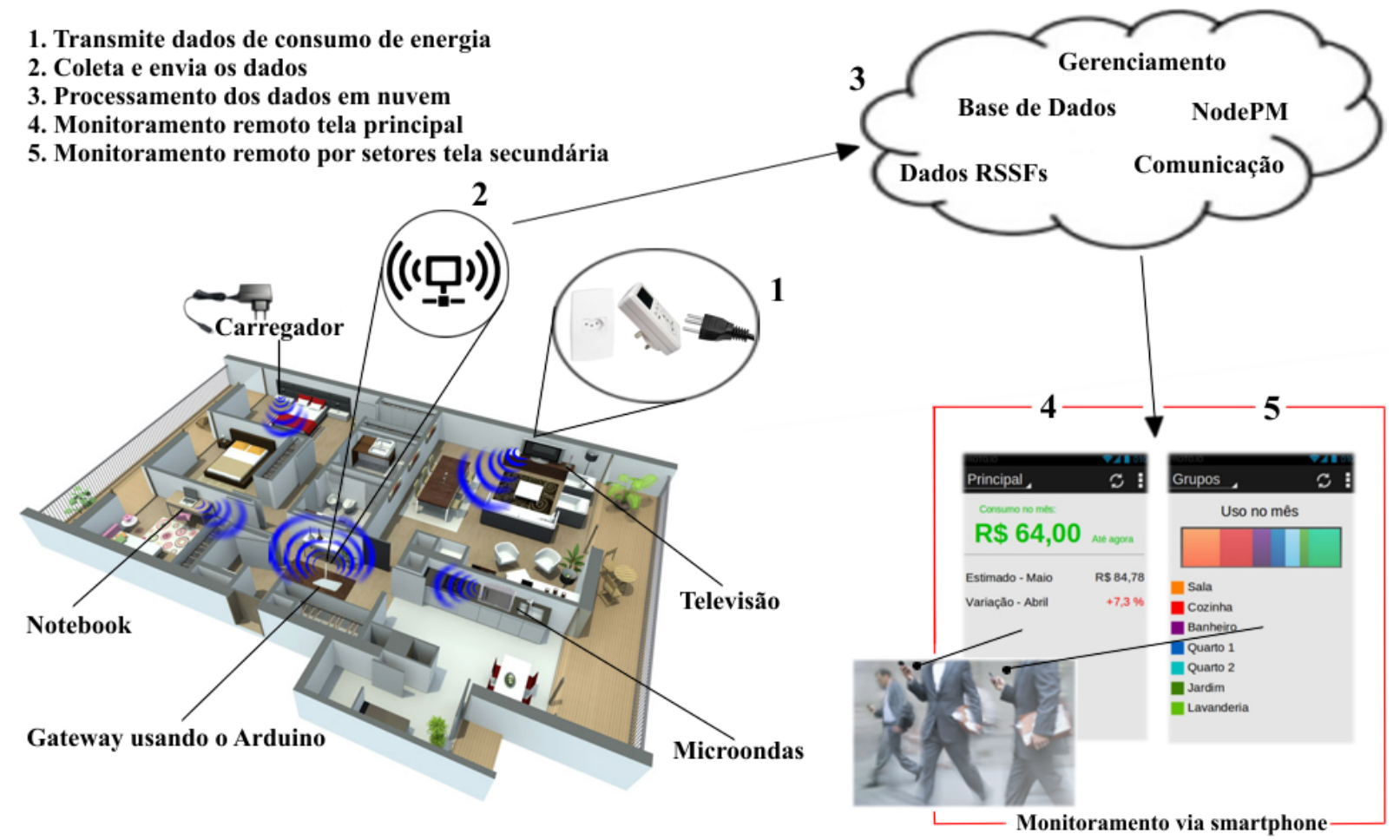

Figura 3.1: Cenário de funcionamento da plataforma.

\footnotetext{
${ }^{1}$ App Engine - Developers, https://developers.google.com/appengine/

${ }^{2} \mathrm{P} 3$ International innovative electronic solutions, http:/ / www.p3international.com

${ }^{3}$ Xbee-pro module datasheet, http:/ / ftp1.digi.com/support/documentation/90000976G.pdf

${ }^{4}$ Arduino, http://www.arduino.cc
} 
dos da RSSF, processa tais dados (detectando novidades) e gerencia (dados de consumo) o envio das informações, sendo possível fazer o monitoramento remoto por meio de um smartphone, por exemplo (Rótulos 4 e 5, Figura 3.1).

Nesse sentido, o usuário recebe os alertas e visualiza as informações mais importantes do consumo de energia como mostra o Rótulo 4 da Figura 3.1. Já no Rótulo 5 da Figura 3.1, é feito o monitoramento por setores, tais como: equipamento, cômodo da casa e/ou toda região de atuação, somente possível por causa da RSSF.

A seguir o wattímetro e o gateway desenvolvidos são apresentados.

\section{Wattímetro desenvolvido para a formação da RSSF}

Como uma das etapas deste trabalho é coletar o consumo de energia dos equipamentos eletrônicos, desenvolveu-se um wattímetro com poder de comunicação sem fio, ilustrado na Figura 3.2, considerando as funcionalidades das RSSFs. Para tanto, integrou-se no wattímetro o XBee (Rótulo 1, Figura 3.2), como módulo de comunicação, o qual utiliza o protocolo ZigBee ${ }^{5}$, amplamente usado em RSSFs. Dessa forma, o wattímetro desenvolvido permite a criação de uma RSSF que coleta informações de consumo de energia dos dispositivos eletrônicos.

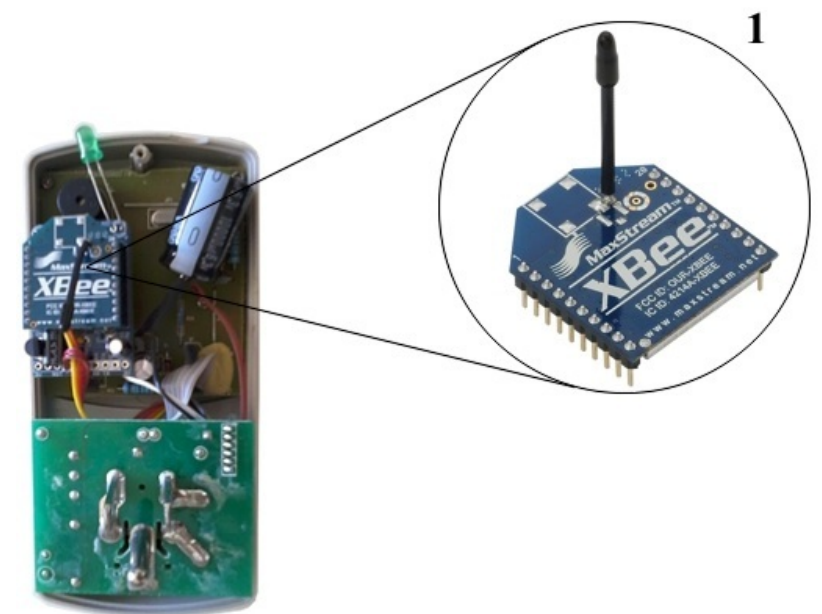

Figura 3.2: Wattímetro desenvolvido com comunicação sem fio via XBee para a formação da RSSF.

A escolha do módulo de comunicação utilizado no wattímetro, o modelo XB24-AWI001, é justificada por dois motivos: (i) baixo consumo de energia; e (ii) área de alcance médio de 40 metros indoor e/ou 120 metros outdoor.

A partir do circuito integrado do wattímetro foi possível saber o quanto um determinado equipamento está consumindo. Para isso, utilizou-se pela lei de Ohm a relação entre tensão $V$ e corrente $I$ para saber a potência $P, P=V * I$. Dessa forma, ao multiplicar a potência $P$ pelo tempo de uso do equipamento, obtêm-se a energia que o equipamento está consumindo em Watt-Hora.

\footnotetext{
${ }^{5}$ ZigBee, http://www.zigbee.org
} 
É fundamental destacar, portanto, que para fazer leituras precisas da potência do equipamento ao fazer a transmissão, estabeleceu-se que o XBee obterá 17 amostras de tensão e corrente espaçadas de $1 \mathrm{~ms}$, ou seja, uma janela de $17 \mathrm{~ms}$ de amostras. Como o sinal na linha elétrica é periódico, isto é, se repete de acordo com a frequência da rede, a qual funciona a $60 \mathrm{~Hz}$, um período de onda possuirá $(1 / 60) \mathrm{ms}$, ou seja, 16,6 ms de amostras. Logo, nossas amostras enviadas de $17 \mathrm{~ms}$ têm informações suficientes para leituras precisas da potência do equipamento. Além disso, o XBee pode ser configurado para ter um número de identificação, como o MAC Address. Tal identificação foi utilizada para reconhecer, por exemplo, qual transmissor está conectado à geladeira ou à televisão.

\section{Construção do gateway com a plataforma Arduino}

Para enviar os dados sensoriados da RSSF e transmiti-los para um servidor em nuvem, foi necessário desenvolver um gateway, ilustrado na Figura 3.3. Para a construção desse gateway, optou-se por utilizar a plataforma Arduino por ser programável, extensível, portável e de baixo consumo de energia.

Como o gateway projetado deve-se tanto comunicar com os diversos módulos XBee quanto ter acesso a uma rede Ethernet, foi necessário expandir o uso do Arduino através de Shields. Assim, utilizaram-se dois Shields (Shield XBee e Shield Ethernet) para fazer a conexão entre a RSSF e o servidor em nuvem. Dessa forma, o Shield XBee (Rótulo 1, Figura 3.3) recebe os dados sensoriados da RSSF e transmite tais dados por meio do Shield Ethernet (Rótulo 2, Figura 3.3) para um servidor em nuvem.

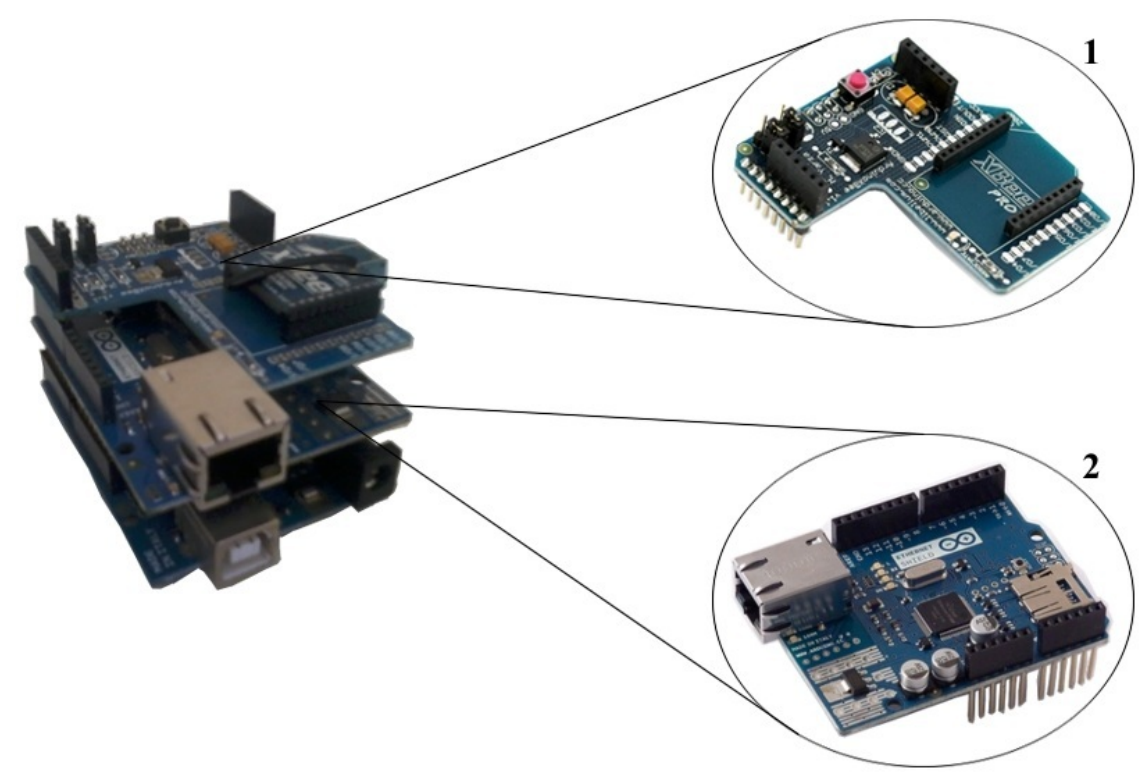

Figura 3.3: Gateway desenvolvido com a plataforma Arduino usando o Shield XBee (Rótulo 1) e o Shield Ethernet (Rótulo 2). 


\subsubsection{Novelty Detection Power Meter (NodePM)}

O NodePM é modelado usando os conceitos de AM, cadeias de Markov e entropia. No Algoritmo 3.1 é descrito o funcionamento do NodePM, o qual consiste de três etapas:

- Primeira etapa, processar os dados por meio de um classificador, K-Nearest Neighbors (KNN) (Linha 2, Algoritmo 3.1), para catalogar o estado comportamental dos equipamentos eletrônicos.

- Segunda etapa, capturar o elemento catalogado na primeira etapa e adicionar no estado comportamental da cadeia de Markov (Linha 3, Algoritmo 3.1).

- Terceira etapa, obter a matriz de probabilidade da cadeia de Markov e calcular o grau de incerteza dos equipamentos eletrônicos, usando a variação da entropia (Linhas 4 e 5, Algoritmo 3.1).

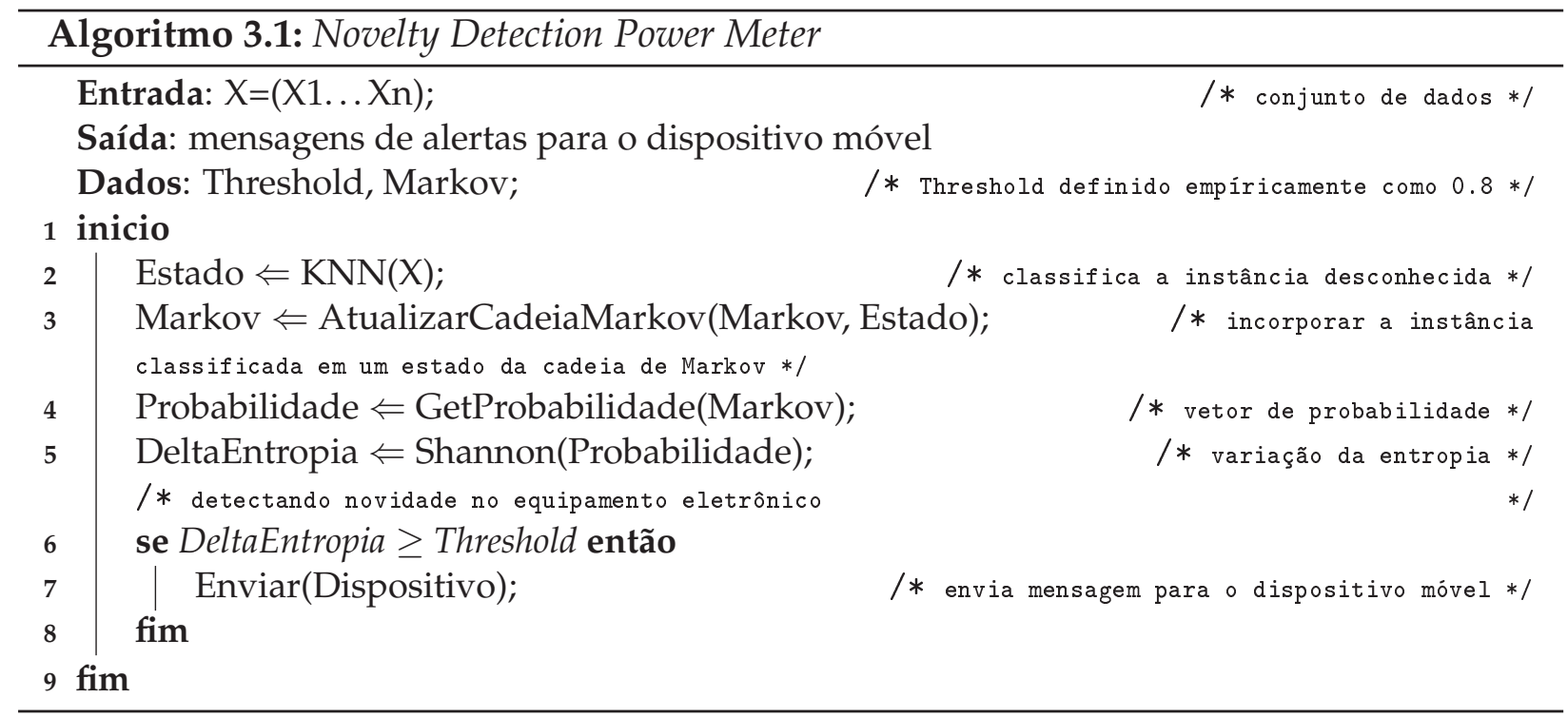

As etapas descritas anteriormente são reorganizadas para um melhor entendimento tanto do NodePM quanto dos conceitos relacionados.

\section{Classificação de padrões comportamentais}

Nesta subseção, é apresentada a técnica escolhida, KNN, para classificar os dados recebidos da RSSF com o intuito de incorporá-los na cadeia de Markov.

A escolha do KNN é justificada por dois motivos: (i) apesar de ser simples, tem mostrado ser uma das técnicas mais eficazes já proposta na literatura; (ii) e, é uma técnica, tradicional e efetiva aplicada em vários problemas de classificação (Yang \& Liu, 1999).

Para facilitar o entendimento da técnica e o seu funcionamento na plataforma, a Figura 3.4 ilustra como os dados de entrada são classificados. Os gráficos da Figura 3.4 representam a potência de um equipamento em função do tempo (minuto), sendo possível perceber 
quatro comportamentos distintos (standby, desligado, normal $^{6}$ e não esperado ${ }^{7}$ ) de consumo de energia.
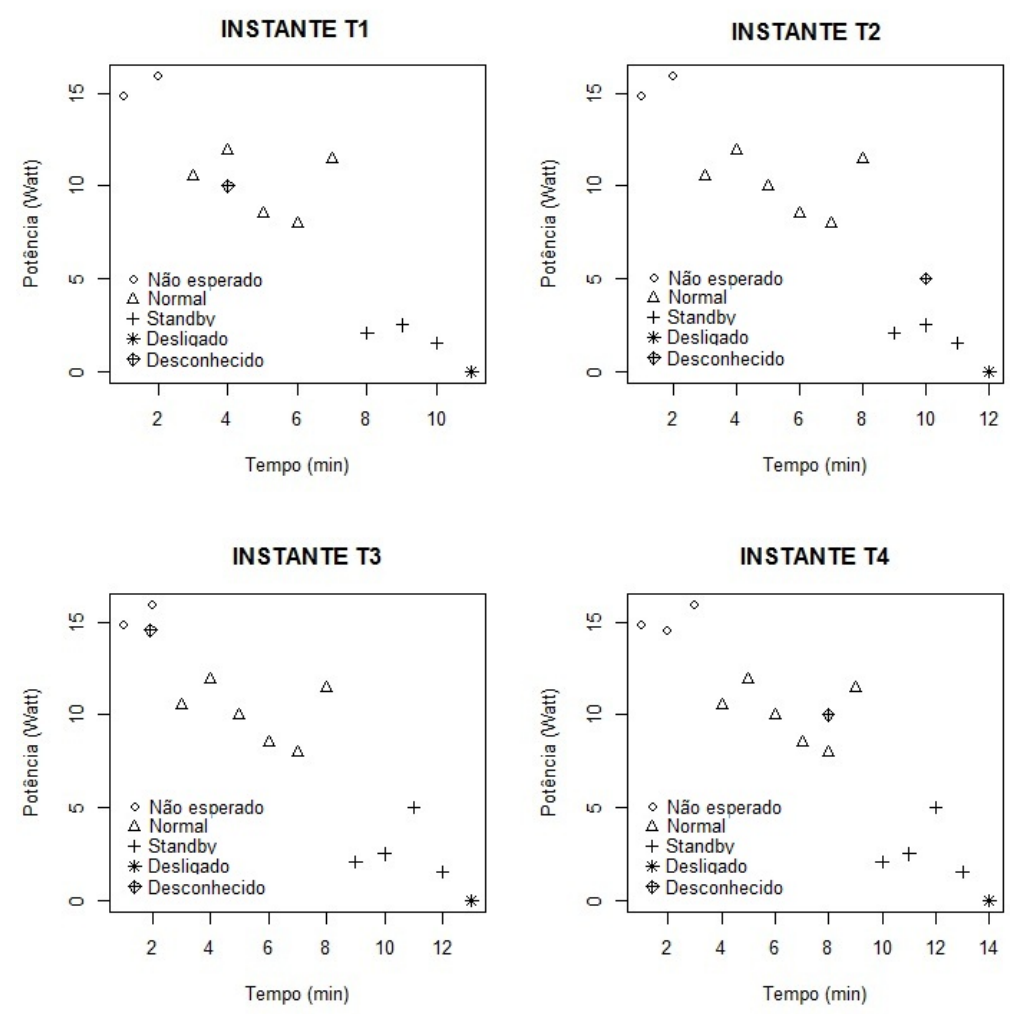

Figura 3.4: Exemplo de classificação do KNN.

Deve-se ressaltar, portanto, que o KNN classifica as instâncias desconhecidas analisando os K vizinhos mais próximos. Neste caso, a instância "desconhecida" no INSTANTE T1 (revisite Figura 3.4) é classificada como uma instância "normal". Após a classificação, é fundamental destacar, que o elemento classificado é adicionado incrementalmente na base de treinamento, com a finalidade do método se adaptar de forma autônoma em ambientes dinâmicos. A adaptação do ambiente, neste trabalho, ocorre a cada 5 segundos, tempo estipulado pela plataforma para enviar os dados. Dessa forma, o INSTANTE T2, T3 e T4 seguem o mesmo processo que o INSTANTE T1.

Assim, a próxima etapa do método consiste em adicionar a instância classificada, a cada instante de tempo, em um estado da cadeia de Markov.

\section{Obtenção de padrões comportamentais}

A obtenção dos padrões comportamentais do NodePM é realizada mediante a cadeia de Markov (Markov, 1971). Assim, conforme o KNN classifica as instâncias desconhecidas, como descrita na etapa anterior, uma nova cadeia de Markov é gerada. Na Figura 3.5 é exibida a matriz de probabilidade e a cadeia de Markov em cada um dos instantes de

\footnotetext{
${ }^{6}$ Representa o equipamento dentro de um padrão, a geladeira por exemplo fica ligada constantemente.

${ }^{7}$ Representa o equipamento fora do padrão e/ou consumindo energia acima do esperado.
} 
tempo, como apresentado anteriormente na Figura 3.4, a fim de representar o comportamento do equipamento naquele instante de tempo.

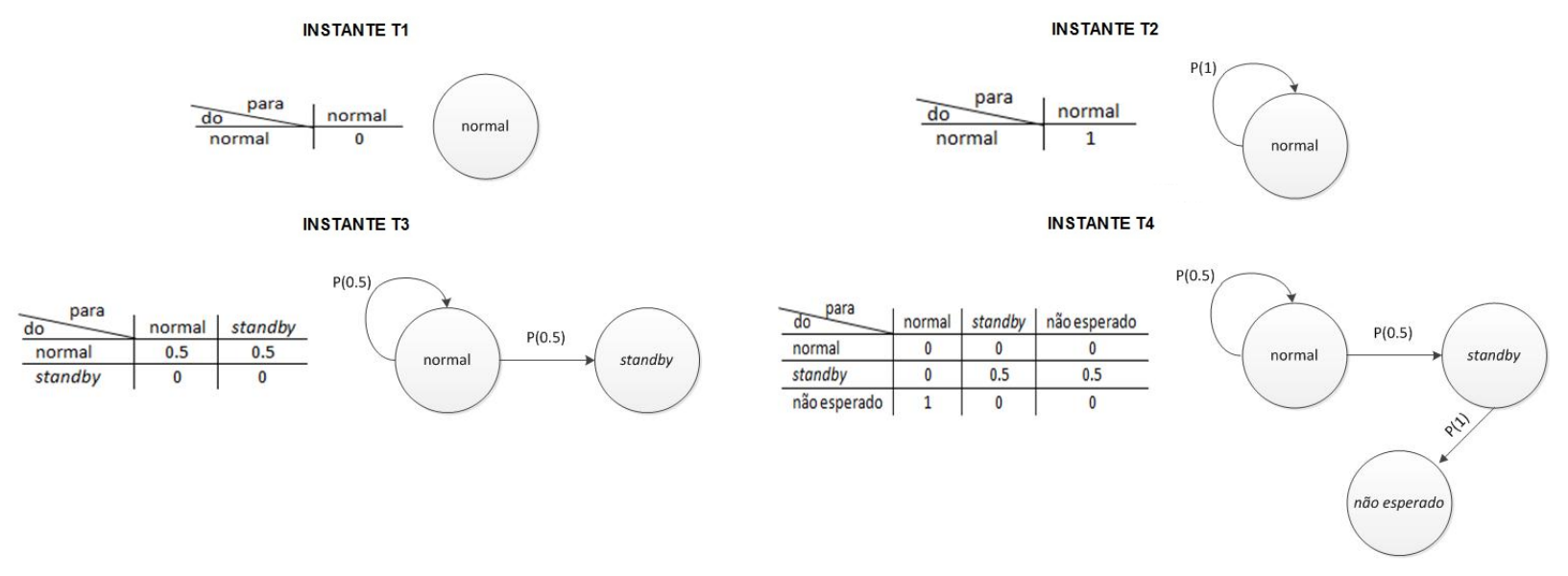

Figura 3.5: Matriz de probabilidade e cadeia de Markov a cada instante de tempo de acordo com a Figura 3.4.

Nesse sentido, a matriz de probabilidade e a cadeia de Markov são atualizadas de acordo com cada nova classificação do KNN (veja o paralelo da Figura 3.4 com a Figura 3.5). Neste caso, no INSTANTE T1 (Figura 3.5) classificou-se a primeira instância como "normal", porém sem transição na cadeia de Markov. No INSTANTE T2 (Figura 3.5), a segunda instância também foi classificada como "normal", no entanto há uma transição entre a primeira e segunda instância classificada, com isso, a matriz de probabilidade é atualizada, apresentando uma transição do estado "normal" para o estado "normal". O INSTANTE T3 e T4 da Figura 3.5 seguem o mesmo processo. Assim, os estados da cadeia de Markov são criados dinamicamente a medida que o KNN classifica o comportamento do equipamento para aquele instante de tempo.

Após classificar, representar o comportamento dos equipamentos mediante a cadeia de Markov e obter as probabilidades a cada instante de tempo, é necessário calcular o grau de incerteza dos equipamentos por meio da entropia da cadeia de Markov.

\section{Detecção de novidades com a variação da entropia da cadeia de Markov}

Com o conjunto das probabilidade das cadeias de Markov gerado, torna-se possível calcular a variação da entropia a cada instante de tempo por meio da equação 2.8, como apresentado na Subseção 2.2.4, e exposta novamente:

$$
E(i)=-\sum_{i=1}^{q} P\left(s_{i}\right) \log _{2}\left(P\left(s_{i}\right)\right)
$$

Nesse sentido, cada interação do usuário com o equipamento gera uma curva que representa as alterações comportamentais do consumo de energia de cada equipamento. A curva pode ser utilizada como uma medida de incerteza, isto é, o nível de incerteza (novidade) das cadeias de Markov pode ser obtida por meio da variação da entropia. 
Logo, detecta-se que o sistema divergiu do esperado, ou seja, ocorreu uma novidade, quando há uma variação significativa na entropia. No próximo capítulo, é feito uma investigação (Seção 4.2) de como as novidades ocorrem mediante o uso da variação da entropia. 


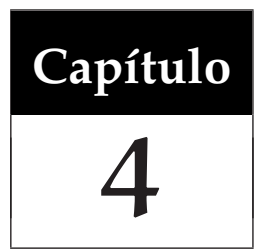

\section{Experimentos e resultados}

$\mathrm{N}$ este capítulo, é apresentada a metodologia utilizada para gerar os experimentos e os resultados obtidos. Para tanto, a validação do método proposto, nomeado NodePM, foi dividida em três etapas. Na primeira etapa, Seção 4.2, apresenta e discute as novidades/anomalias encontradas no consumo de energia dos equipamentos eletrônicos. Na segunda etapa, Seção 4.3, é realizado uma avaliação de desempenho tendo como parâmetro de comparação o Self-Organizing Novelty Detection (SONDE), descrito na Subseção 4.1.2. Por fim, na terceira etapa, Seção 4.4, a eficiência em detectar anomalias no consumo de energia dos equipamentos eletrônicos é validada.

\subsection{Metodologia}

Segundo Jain (1991), cada sistema computacional possui a sua particularidade. Dessa forma, a avaliação de desempenho torna-se algo peculiar para cada sistema avaliado. Nesse sentido, não é comum usar a mesma metodologia de avaliação para sistemas computacionais diferentes. Para esta pesquisa três etapas compõem a avaliação realizada, sendo elas: (i) a definição da base de dados; (ii) a escolha do baseline para o método; e (iii) o ambiente monitorado. A seguir, cada uma dessas etapas é descrita.

\subsubsection{Base de dados}

O método proposto utilizou um conjunto de dados (dataset), contendo informações reais sobre a interação do usuário com o equipamento eletrônico. Essa base de dados possui quatro atributos, sendo eles: (i) identificador do equipamento atribuído pelo sensor; (ii) potência em Watt; (iii) a data de utilização do equipamento; (iv) e o tempo de uso do equipamento naquele momento.

Deve-se ressaltar, no entanto, que o único atributo normalizado para o tipo inteiro é a data, a qual representa o número de dias decorridos a partir de uma data fixa. Esse 
atributo é normalizado pela própria plataforma. Esta utiliza o $\mathrm{JSON}^{1}$ para transmitir os dados em um formato padronizado. Assim, é importante destacar que o método não necessita fazer qualquer normalização dos atributos recebidos.

Após o envio dos dados, foram realizadas nove partições das amostras do conjunto de dados coletados. Cada partição contém um conjunto de dados dos dias das semanas. Para o primeiro experimento, Secção 4.2, as nove partições foram utilizadas para descobrir os tipos de anomalias. Para o segundo experimento, Seção 4.3, cada elemento do conjunto de dados dos dias das semanas foram dividida em 25\% de instâncias de treinamento e 75\% em instâncias de testes. Essa técnica é conhecida como hold-out, no qual divide a base de dados em dois conjuntos (conjunto de treino e teste) (Mitchell, 1997). Como o objetivo do terceiro experimento, Seção 4.4, é determinar o quanto o usuário poderia reduzir o consumo de energia, não há a necessidade de usar a técnica hold-out. Assim, apenas as partições contendo o conjunto de dados dos dias das semanas foram utilizadas.

\subsubsection{O baseline para o algoritmo proposto}

Para realizar uma análise de desempenho do NodePM, como será feito na Seção 4.3, foi necessário obter um baseline. Para tanto, o baseline foi o Self-Organizing Novelty Detection (SONDE) (Albertini \& Mello, 2007). A SONDE é uma rede neural que adapta incrementalmente sua estrutura de conhecimento (neurônio), com o objetivo de detectar novidades em ambientes dinâmicos. Para isso, a SONDE classifica em um mesmo neurônio padrões de entradas similares. Quando nenhum neurônio é capaz de classificar um padrão de entrada, um novo neurônio é criado indicando uma novidade no ambiente.

A escolha da SONDE pode ser justificada por quatro motivos: (i) a SONDE pode ser utilizada em qualquer sistema e/ou aplicação independente da base de dados; (ii) o método detecta eventos inesperados em ambientes dinâmicos; (iii) o treinamento e a adaptação são realizados sem a intervenção de um especialista; e (iv), por fim, a SONDE obteve melhor desempenho quando comparado com outros métodos da literatura (Marsland et al., 2002; Albertini \& Mello, 2007).

\subsubsection{Descrição do ambiente monitorado}

Para produzir resultados com boa precisão, foi criado um ambiente real para monitorar o consumo de energia dos equipamentos eletrônicos em uma residência. Nesse cenário, os equipamentos se localizavam em cômodos diferentes e, por conveniência, o gateway Arduino estava junto do roteador para comunicar com a Internet. O monitoramento do consumo de energia dos equipamentos eletrônicos, sumarizados na Tabela 4.1, foram feitas durante os anos de 2012 (Julho, Agosto, Setembro, Novembro e Dezembro) e 2013 (Janeiro, Fevereiro, Junho e Julho) com período de tempo variável.

\footnotetext{
${ }^{1}$ JSON, http://www.json.org/
} 
Tabela 4.1: Conjunto de equipamentos eletrônicos monitorados através da plataforma desenvolvida (revisite a Figura 3.1).

\begin{tabular}{|c|c|}
\hline \multicolumn{2}{|c|}{ Equipamentos eletrônicos } \\
\hline Geladeira & Roteador \\
\hline Cafeteira & Televisão \\
\hline Microondas & Chuveiro \\
\hline Tanquinho & Computador \\
\hline
\end{tabular}

\subsection{Experimentos de detecção de novidades com o NodePM}

Para alcançar um dos objetivos deste trabalho, foi necessário investigar como as novidades ocorrem. Para tanto, utilizou-se as partições do conjunto de dados para a realização dos experimentos. Com isto, foi possível identificar dois tipos de novidades: qualitativa e quantitativa.

- A primeira ocorre quando o equipamento eletrônico tem uma mudança abrupta no seu comportamento padrão, ou seja, ocorreu uma troca não habitual no seu estado, passando do estado $x$ para o estado $y$, situação essa que não era esperado. (qualitativa)

- A segunda acontece quando o equipamento eletrônico começa a consumir mais energia que o esperado durante um determinado período, ou seja, passando do estado usual do usuário. (quantitativa)

A seguir alguns experimentos são discutidos, apresentando como acontece a novidade.

A Figura 4.1 apresenta o primeiro tipo de novidade, como descrito anteriormente, para um equipamento eletrônico (geladeira). O Gráfico $4.1 \mathrm{~b}$ apresenta a variação da entropia em função do tempo (minuto), no qual é possível notar tanto o comportamento padrão (sem novidade) entre o período de 0 a 54 e 71 a 200 minutos quanto o comportamento não esperado (com novidade) entre o período de 55 a 70 minutos. Como o Gráfico 4.1a apresenta a potência consumida em função do tempo (minutos) é essencial observar o comportamento da geladeira a cada período. Nesse sentido, no intervalo de tempo entre 55 e 70 (Gráfico 4.1b) nota-se uma alteração repentina na entropia, causada pela mudança no padrão de comportamento da geladeira (Gráfico 4.1a). Esta mudança abrupta surgiu devido ao desligamento da geladeira durante 15 minutos (veja o Gráfico 4.1a no intervalo de 55 a 70), ou seja, o equipamento saiu do seu estado habitual o qual não era esperado. Apesar disso, a variação da entropia começa a estabilizar depois dos 66 minutos (Gráfico 4.1b). Essa estabilização pode ocorrer por dois motivos: (i) a primeira é devido à mudança de hábito do usuário (por exemplo, causada por feedback por intermediação do smartphone); e (ii) a segunda é que no decorrer do tempo o método considera que aquela novidade já não é algo inesperado. 


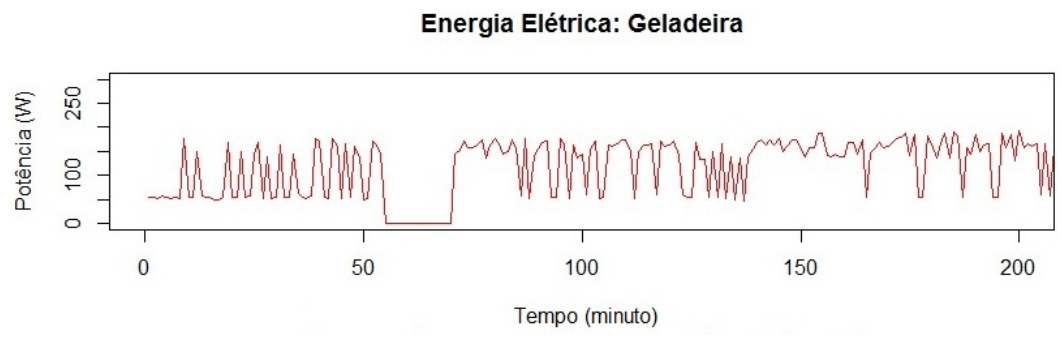

(a) Consumo de energia elétrica da geladeira durante um período acontecendo algo inesperado entre o período de 55 a 70 minutos.

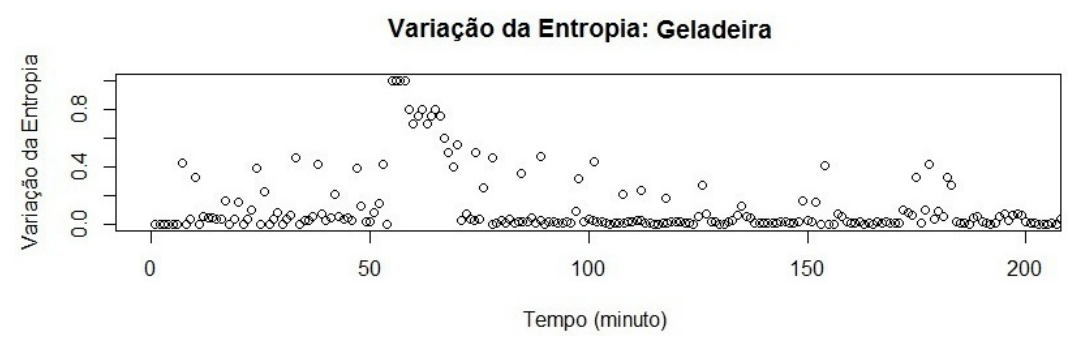

(b) Detectando novidade com uma mudança inesperada no comportamento da geladeira de acordo com o Gráfico 4.1a.

Figura 4.1: Detecção de novidades causada pela mudança no comportamento do consumo de energia da geladeira.

O segundo tipo de novidade (Figura 4.2) está relacionado com o consumo elevado de energia elétrica do roteador durante um determinado período (quantitativo). O Gráfico 4.2a representa bem esse comportamento, expondo a potência consumida em função do tempo (minuto). Nesse gráfico é perceptivo um elevado pico de consumo de energia no período de 36 a 43 minutos. Sendo assim, o Gráfico $4.2 b$ que representa a variação da entropia em função do tempo (minuto) constata a ocorrência de uma novidade no mesmo instante de tempo que o Gráfico 4.2a, devido a uma mudança abrupta na variação da entropia. Vale destacar que a estabilização da variação da entropia ocorre similar ao primeiro tipo de novidade, ou seja, a estabilização pode ocorrer por dois motivos, como descrita anteriormente.

A Figura 4.3 apresenta o consumo de energia elétrica de um tanquinho. Este eletrodoméstico não é ligado constantemente na tomada. Por isso, os dados de consumo desse equipamento não são comportados, diferentemente da geladeira e/ou roteador, os quais ficam ligados constantemente. Equipamentos que possuem características semelhantes a do tanquinho, tais como microondas, cafeteira e/ou televisores, apesar de possuir dados não comportados, detectam as mesmas novidades (qualitativa e quantitativa) descritas anteriormente. Os gráficos 4.3a e 4.3b ilustram esse cenário. Nota-se que no inicio da $3^{a}$ semana (Gráfico 4.3b) ocorreu um aumento na variação da entropia. Tal aumento é explicado por dois motivos, sendo eles: (i) o aumento no consumo da energia elétrica na $3^{\mathrm{a}}$ semana (Gráfico 4.3a) comparado com as duas primeiras semanas (quantitativa); e (ii) a mudança de hábito do usuário no inicio da $3^{\mathrm{a}}$ semana (qualitativa). 


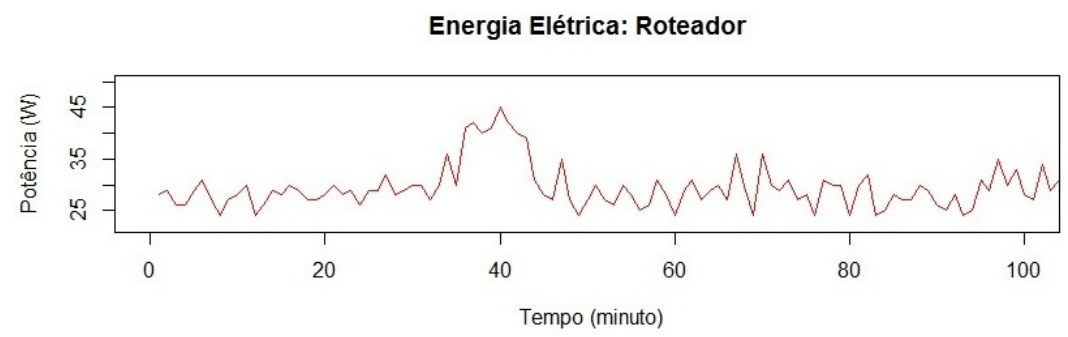

(a) Consumo de energia elétrica do roteador durante um determinado período.

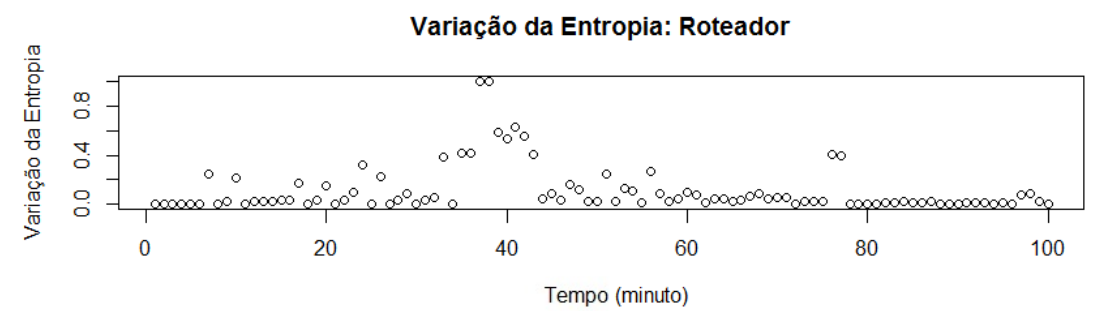

(b) Detectando novidade no mesmo instante de tempo que o Gráfico 4.2a.

Figura 4.2: Detecção de novidade com o aumento do consumo inesperado de energia elétrica do roteador.

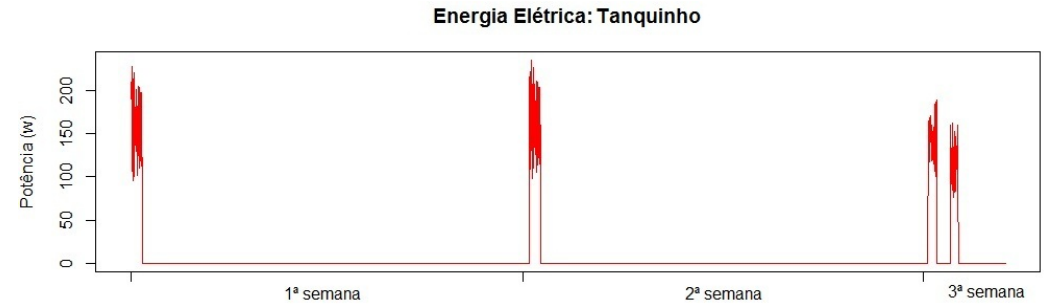

(a) Consumo de energia elétrica do tanquinho, acontecendo na $3^{\mathrm{a}}$ semana um aumento significativo no consumo de energia e/ou uma mudança de hábito do usuário.

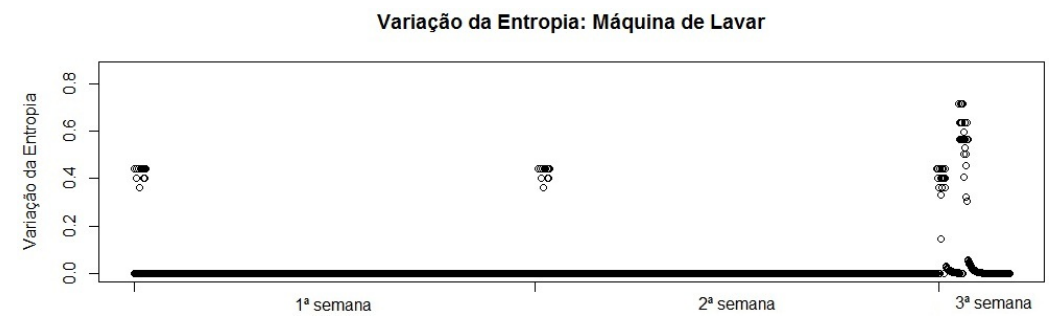

(b) Detectando novidade no mesmo período que o Gráfico 4.3a.

Figura 4.3: Detectando novidade no consumo de energia do tanquinho, o qual possui dados não comportados.

Apesar de existir dois tipos de novidades, ambas podem estabilizar no erro como ocorrido nos gráficos $4.1 \mathrm{~b}$ e $4.2 \mathrm{~b}$. Tal situação é considerada uma vantagem caso o usuário não queira mudar o seu comportamento diante, por exemplo, do consumo exagerado de energia elétrica. Logo, o NodePM não irá incomodá-lo com os possíveis alertas. 


\subsection{Avaliação de desempenho do NodePM com a SONDE}

Esta seção avalia o desempenho do NodePM, considerando as seguintes medidas de desempenho: sensibilidade (conhecida por alguns autores como taxa de detecção), precisão, especificidade e acurácia. Essas medidas, apresentadas a seguir, são calculadas a partir de uma matriz de confusão ilustrada na Figura 4.4, no qual avalia os resultados com base nas perdas causadas.

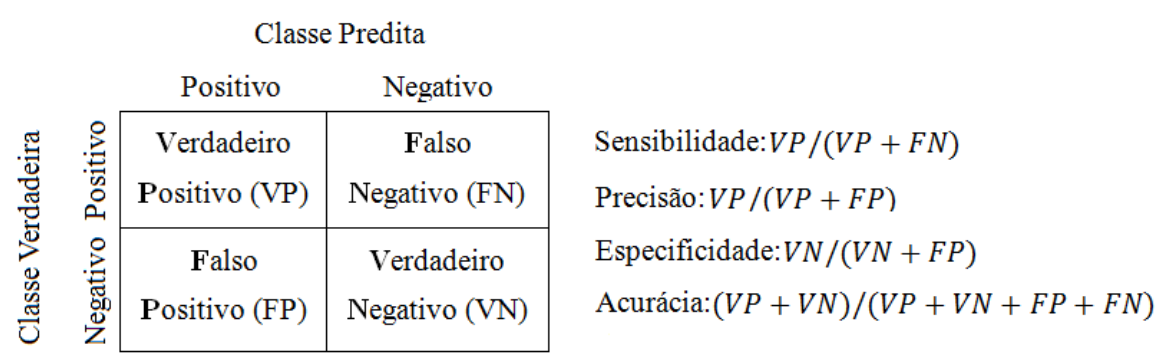

Figura 4.4: Medidas de desempenho calculadas a partir da matriz de confusão.

Segundo Fawcett (2006), tais medidas possuem características inerentes, sendo a sensibilidade o total de amostras cuja classe resultante é realmente positiva (verdadeiros positivos); a precisão é o total de exemplos classificados como positivo, mas que nem sempre são, ou seja, os verdadeiros negativos; já a especificidade é o oposto da sensibilidade, importando somente em classificar como negativo os exemplos que de fato são negativos (falsos positivos) e a acurácia permitirá analisar o quanto preciso o método classifica adequadamente o comportamento de um equipamento.

Os conjuntos de parâmetros estabelecidos para realizar a avaliação de desempenho são apresentados pela Tabela 4.2. O sistema é avaliado com a alteração do dataset (1 semana e 2 semanas), com a mudança do equipamento (geladeira e roteador), e, com a troca dos métodos (NodePM e SONDE). Tais métodos utilizam o dataset que contém informações reais da interação do usuário com o equipamento. Cada conjunto de parâmetros foi executado 11 vezes com o intuito de alcançar uma estabilidade nos resultados. Os resultados são apresentados na Figura 4.5, com um intervalo de confiança de 95\% de acordo com a distribuição $t$-student.

O Gráfico 4.5 apresenta a porcentagem dos resultados obtidos dos experimentos de E1 até E8 (Tabela 4.2) em função das medidas sensibilidade, precisão, especificidade e acurácia para o dataset de 1 e 2 semanas. O resultado destaca que o método NodePM possui um desempenho superior em relação a SONDE quando considerado o dataset de 1 semana, independente do equipamento utilizado (experimentos $\{(\mathrm{E} 1, \mathrm{E} 5),(\mathrm{E} 2, \mathrm{E} 6)\})$. Isso ocorre devido ao NodePM usar uma abordagem supervisionada, ou seja, a base de dados possuem exemplos que estão rotulados com uma classe predita. Logo, o método não necessita de muitas instâncias de treinamento para atingir bons resultados, pois com o 
Tabela 4.2: Conjunto de parâmetros escolhidos para serem avaliados.

\begin{tabular}{c||ccc}
\hline Experimento & Método & Dataset & Equipmento \\
\hline \hline E1 & NodePM & 1 Semana & Geladeira \\
E2 & NodePM & 1 Semana & Roteador \\
E3 & NodePM & 2 Semanas & Geladeira \\
E4 & NodePM & 2 Semanas & Roteador \\
E5 & SONDE & 1 Semana & Geladeira \\
E6 & SONDE & 1 Semana & Roteador \\
E7 & SONDE & 2 Semanas & Geladeira \\
E8 & SONDE & 2 Semanas & Roteador \\
\hline
\end{tabular}

dataset de 2 semanas o seu desempenho foi significativo (aproximadamente 3\% de aumento, experimentos de E1 a E4). Porém, ao levar em consideração o dataset de 2 semanas os papéis se invertem, ou seja, a SONDE tem melhor desempenho que o NodePM, independente do equipamento utilizado (experimentos $\{(\mathrm{E} 3, \mathrm{E} 7),(\mathrm{E} 4, \mathrm{E} 8)\})$. Isso é coerente, posto que a SONDE é uma rede neural artificial não-supervisionada e auto-organizável. Consequentemente, é necessário ter um dataset maior para que os neurônios da SONDE se adapte, de forma incremental, de acordo com novos padrões de entrada. Por isso, o seu elevado desempenho (aproximadamente 13\% de aumento, experimentos de E5 a E8) está relacionado com o aumento das instâncias de treinamento.

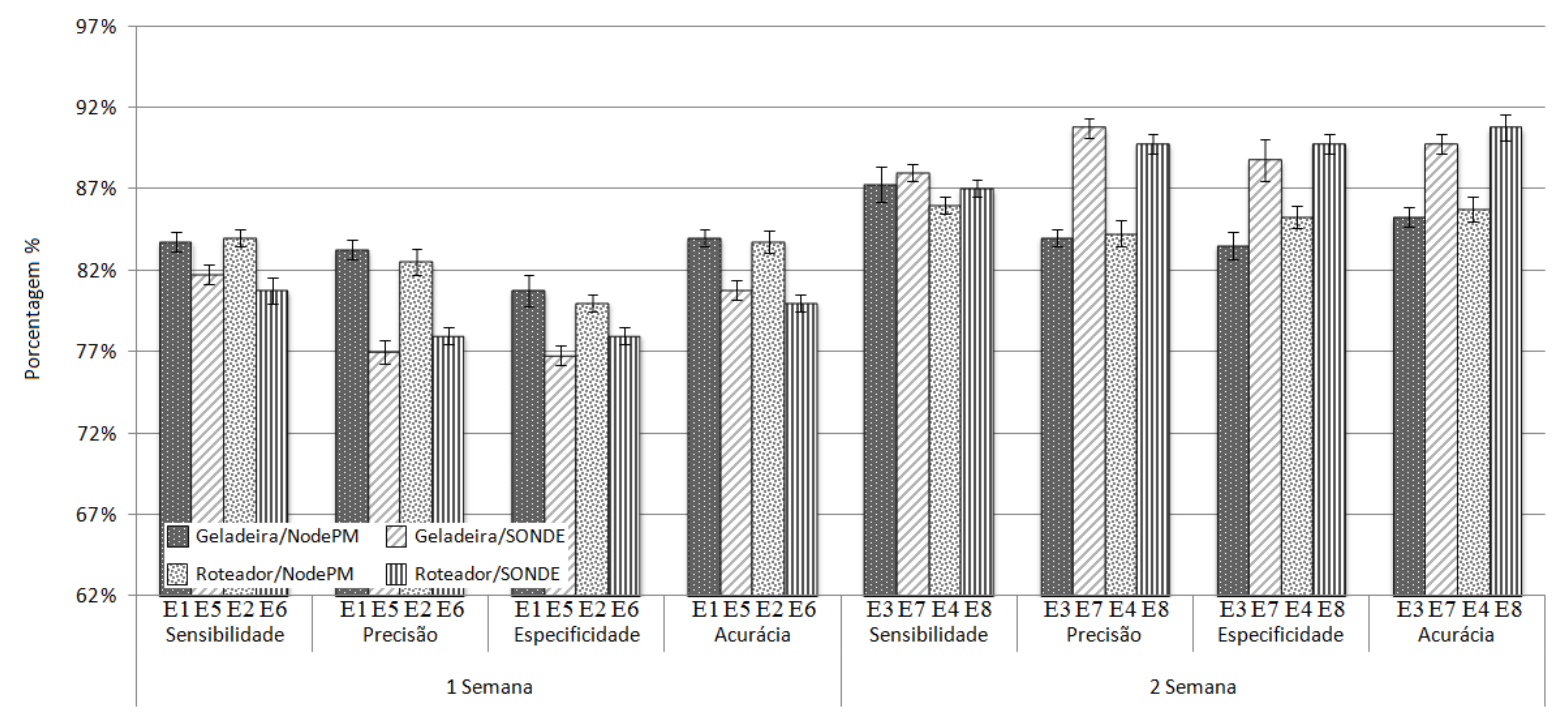

Figura 4.5: Análise de desempenho do NodePM de acordo com a Tabela 4.2.

\subsubsection{Análise das influências dos parâmetros}

Esta subseção apresenta as análises das influências do conjunto de parâmetro consideradas na Tabela 4.2 em função das medidas de desempenho. As análises foram feitas utilizando um modelo de regressão multivariado (Jain, 1991), no qual inclui uma relação causal com mais de duas variáveis. Neste caso, o comportamento de uma medida de de- 
sempenho é explicado por mais de um parâmetro. Dessa forma, é possível analisar quais parâmetros e/ou suas combinações que mais influenciaram nos resultados.

Na Tabela 4.3, são apresentados os parâmetros métodos, dataset e equipamento com as respectivas letras A, B e C. As combinações de duas ou mais letras são os percentuais das interações entre os parâmetros. Nota-se que o parâmetro com mais influência para todas as medidas de desempenho é justamente o dataset (B), no qual também pode ser observado nos resultados pelos pares dos experimentos (E1,E3), (E2,E4), (E5,E7), (E6, E8). O segundo parâmetro com mais influência é a combinação do dataset com o método (AB). Tal influência faz sentido, pois é relacionada com a forte interação que o parâmetro A possui com o B. Deve-se ressaltar, que o parâmetro com menos influência é o equipamento independente do conjunto de parâmetro considerado. Essas afirmações estatísticas evidenciam a eficácia do NodePM na plataforma desenvolvida.

Tabela 4.3: Influência dos parâmetros em função das medidas de desempenho.

\begin{tabular}{l||ccccccc}
\hline Medidas de Desempenho & $\mathbf{A}(\%)$ & $\mathbf{B ( \% )}$ & $\mathbf{C}(\%)$ & $\mathbf{A B}(\%)$ & $\mathbf{B C}(\%)$ & $\mathbf{A C}(\%)$ & $\mathbf{A B C}(\%)$ \\
\hline \hline Sensibilidade & 3,06 & 81,05 & 2,25 & 12,25 & 0,57 & 0,25 & 0,57 \\
Precisão & 0,17 & 59,14 & 0,02 & 39,9 & 0,07 & 0,02 & 0,68 \\
Especificidade & 1,09 & 77,85 & 0,82 & 19,16 & 0,38 & 0,12 & 0,58 \\
Acurácia & 0,64 & 64,97 & 0,07 & 33,16 & 0,95 & 0,01 & 0,02 \\
\hline
\end{tabular}

\subsubsection{Discussão dos resultados}

Com base nos resultados deste primeiro planejamento de experimento, constatou-se claramente que o NodePM foi viável na plataforma. Porém, cada método teve suas peculiaridades. Assim sendo, a escolha do método ficou intrínseco ao dataset (veja Tabela 4.3), visto que os dados coletados em tempo real da interação do usuário com o equipamento possuem características distintas. Dessa forma, se o usuário utilizar equipamentos que são ligados constantemente, tais como geladeira e/ou roteador, no qual possuem mais dados com interação, o mais adequado é utilizar a SONDE (veja Figura 4.5, experimentos E7 e E8). Porém, caso o usuário interaja com equipamentos, tais como microondas, tanquinho e/ou cafeteira, nos quais os aparelhos não são ligados constantemente tendo poucos dados de interação, o mais adequado é o NodePM (veja Figura 4.5, experimentos E1 e E2).

\subsection{Avaliação de desempenho com o NodePM}

Nesta seção, é avaliado o desempenho do NodePM em detectar anomalias do consumo de energia nos equipamentos eletrônicos. O objetivo é comparar a eficiência do sistema proposto em relação aos sistemas tradicionais (que, por exemplo, não apresentam informações do consumo de energia para os usuários).

Os experimentos foram realizados considerando dois parâmetros primários, sendo 
eles: (i) o uso ou não do NodePM; e (ii) o período de monitoramento (1, 2 e 3 semanas). Como o objetivo do planejamento é determinar o quanto o usuário poderia reduzir o seu consumo de energia, utilizou-se a soma do consumo de energia dos equipamentos eletrônicos medida em kWh como variável de resposta. Para tanto, foi necessário fixar dois parâmetros secundários: (i) tipos de anomalias (qualitativa e quantitativa, descrita na Seção 4.2); e (ii) informações do consumo de energia, como ilustrado na Figura 4.6 (buscando, por exemplo, identificar equipamentos em modo standby ${ }^{2}$ ). Nesse sentido, as configurações de cada conjunto de parâmetro, sumarizadas na Tabela 4.4, foram executadas 12 vezes, tendo como referências comparativas os experimentos de A4 a A6.

Tabela 4.4: Conjunto de parâmetros selecioandos para serem avaliados.

\begin{tabular}{c||cc}
\hline Experimento & Usando a proposta & Período de monitorado \\
\hline \hline A1 & NodePM & $1^{\text {a Semana }}$ \\
A2 & NodePM & $2^{\text {a Semana }}$ \\
A3 & NodePM & $3^{\text {a Semana }}$ \\
A4 & - & $1^{\text {a Semana }}$ \\
A5 & - & $2^{\text {a Semana }}$ \\
A6 & - & $3^{\text {a Semana }}$ \\
\hline
\end{tabular}

A Figura 4.7 apresenta os resultados da energia consumida obtida dos experimentos A1 a A6 em função do período de monitoramento. Com a finalidade de realizar uma validação estatística sobre os resultados, duas etapas foram necessárias: (i) teste sobre os conjuntos a fim de verificar a adequação a normalidade, isto é, analisar se os conjuntos podem ser considerados como distribuições normais; e (ii) teste estatístico de comparação entre os conjuntos. Para a primeira, foi utilizado o Shapiro-Wilk normality test, o qual apresentou os seguintes p-valores para os conjuntos de A1 até A6: \{0.023, 0.300, 0.043, 0.024, 0.009 e 0.790$\}$. Assim, notou-se que, com exceção de A2 e A6, os demais conjuntos tem a hipótese de adequação à normalidade rejeitada considerando $95 \%$ de confiança. Isso implica no uso de métodos não paramétricos de comparação entre os conjuntos, sendo indicado para este caso o Wilcoxon rank sum test (segunda etapa do processo de validação estatística).

Nesse sentido, ao utilizar Wilcoxon rank sum test como teste de comparação entre os conjuntos (A1, A4), (A2, A5), e (A3, A6) os seguintes p-valores foram obtidos: $\{0.214,0.003$ e 0.000 , com $95 \%$ de confiança. Através destes resultados, notou-se que para o conjunto dos valores de uma semana não houve estatisticamente diferenças significativas (experimentos A1 e A4 da Figura 4.7). Esta situação é derivada da taxa de verdadeiro positivo obtida pelos experimentos $\{(\mathrm{E} 1, \mathrm{E} 5)$; (E3, E7) $\}$ da Tabela 4.2. Isto é, o NodePM estava ajustando o seu modelo (matriz de probabilidade e cadeia de Markov, revisite a Seção 3.1.2) mediante os dados enviados da RSSF. Entretanto, estatisticamente, para o período de 2

\footnotetext{
${ }^{2}$ Equipamentos eletrônicos em modo standby gastaram em média 8,37\% do consumo de energia de acordo com os dados coletados da plataforma desenvolvida
} 


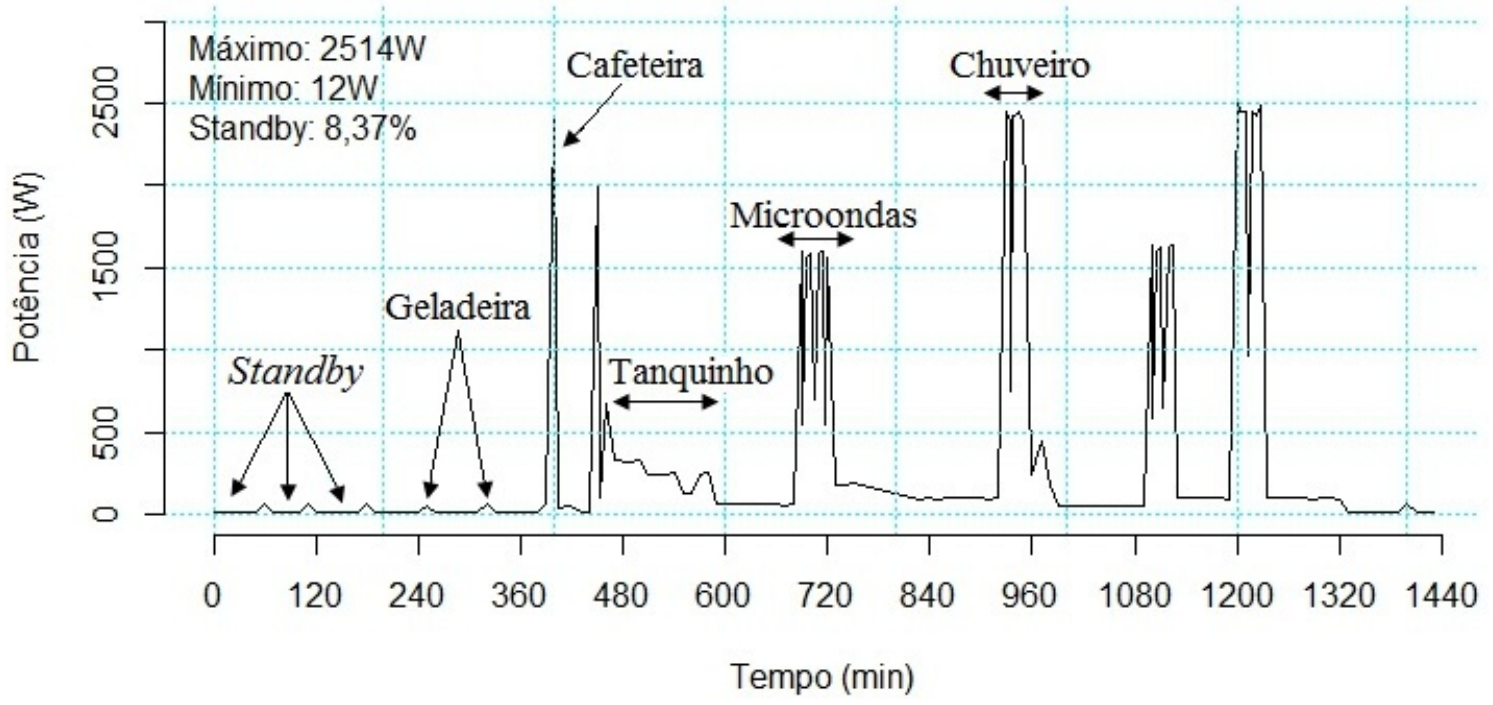

Figura 4.6: Usando a plataforma desenvolvida para observar o consumo de energia gasto pelo usuário em um período de 24 horas, identificando equipamentos ociosos, os quais gastam, por exemplo, uma parte considerável do tempo em modo standby.

e 3 semanas, há uma redução de 11,4\% e 13,7\% do consumo de energia (experimentos $\{(\mathrm{A} 2, \mathrm{~A} 5) ;(\mathrm{A} 3, \mathrm{~A} 6)\}$ da Figura 4.7) quando a proposta é utilizada e, consequentemente, um aumento na taxa de verdadeiro positivo do NodePM (\{(E2, E6); (E4, E8)\} da Tabela 4.2). Isto mostra que o NodePM ajustou o seu modelo de forma incremental (treinamento dinâmico) através das informações enviadas dos wattímetros, apresentando desempenho satisfatório independente do período monitorado (inverno ou verão, por exemplo, Subseção 4.1.3) e do equipamento utilizado.

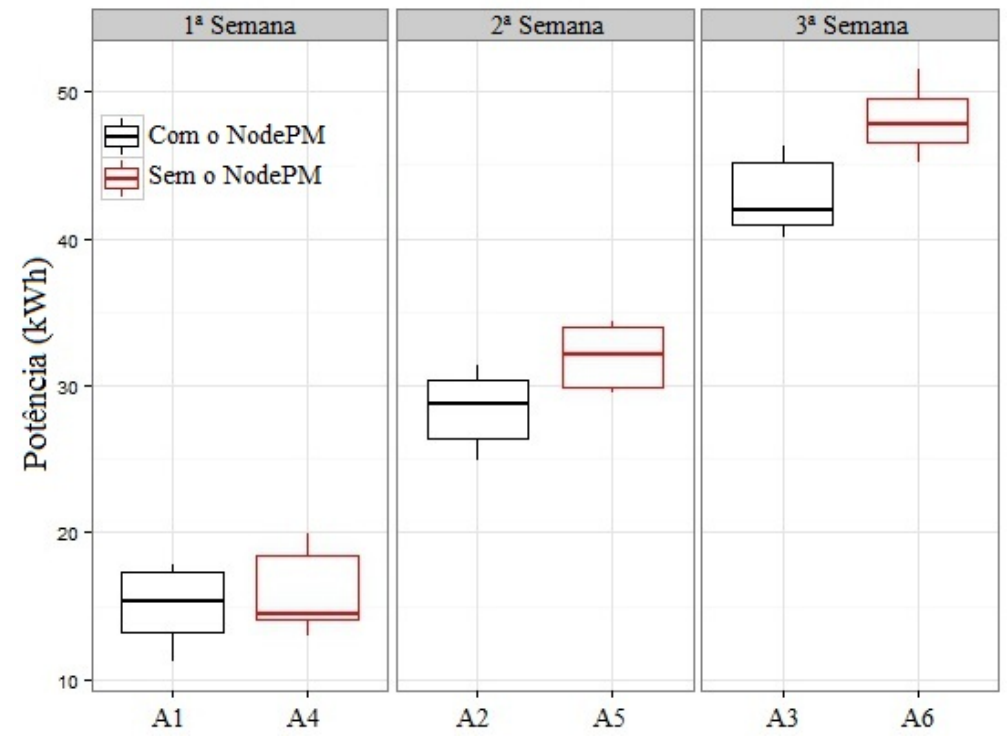

Figura 4.7: Análise de desempenho do NodePM de acordo com a Tabela 4.4. 


\subsubsection{Discussão dos resultados}

Com base nos resultados do segundo planejamento de experimento, observou-se que as mudanças de comportamento de mais longo prazo dos equipamentos eletrônicos não afetaram o desempenho da proposta (veja Figura 4.7, experimentos A2 e A3). Por exemplo, a geladeira que tende a apresentar oscilações no consumo de energia dependendo do período do ano, bem como a sua interação com o usuário. Esta situação foi observada, devido aos diferentes períodos que os equipamentos eletrônicos foram monitorados (veja Subseção 4.1.3). Além disso, durante os experimentos, notou-se que os usuários possuem comportamento diferente no final de semana em relação aos demais dias, e essa situação não afetou o desempenho da proposta. 



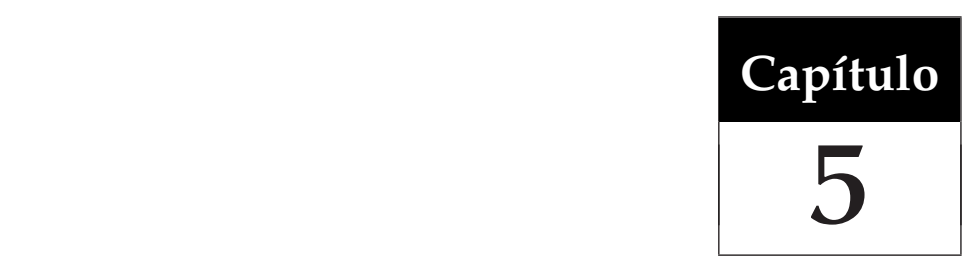

\section{Conclusão}

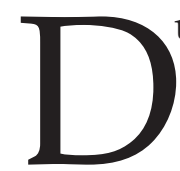
urante o desenvolvimento desta pesquisa, notou-se a importância de utilizar uma RSSF para coletar informações do consumo de energia elétrica em uma residência. Nesse cenário, observou-se a necessidade de usar técnicas de detecção de novidades no consumo de energia para os equipamentos eletrônicos. Nesse sentido foi proposto o NodePM, um algoritmo que considera a entropia da cadeia de Markov com o auxílio do KNN para detectar novidades. Objetivando comprovar a viabilidade do NodePM em um ambiente real, desenvolveu-se uma plataforma de monitoramento remoto do consumo de energia elétrica para coletar os dados do consumo de energia dos equipamentos eletrônicos.

Uma extensa avaliação e experimentação permitiu avaliar, considerando diferentes cenários e parâmetros, a eficiência do NodePM. Através de uma investigação foi possível encontrar dois tipos de novidades, qualitativa e quantitativa. Além disso, os resultados apresentados mediante o planejamento de experimentos foram promissores, sendo dois deles claramente notáveis: (i) desempenho superior em relação a SONDE quando considerado o dataset de 1 semana, independente do equipamento; e (ii) redução de 13,7\% do consumo de energia quando comparado com o sistema tradicional. Logo, os resultados de tais experimentos obtidos mediante análise estatística evidenciam a viabilidade do NodePM.

\subsection{Principais contribuições}

As principais contribuições desta dissertação são apresentadas a seguir:

- Análise dos trabalhos relacionados com o intuito de investigar uma lacuna para esta pesquisa, bem como formalizar a fundamentação teórica.

- O desenvolvimento de um protótipo para coletar dados do consumo de energia dos equipamentos eletrônicos em tempo real. 
- A proposta e implementação de um algoritmo, NodePM, baseado em técnicas probabilísticas para detectar novidades no consumo de energia dos equipamentos eletrônicos.

- O emprego das técnicas de avaliação de desempenho para quantificar o NodePM em cenários distintos.

É fundamental destacar que as principais contribuições foram apresentadas em formas de artigos. A seguir, são apresentadas as listas de publicações realizadas durante o mestrado.

\subsection{Produção científica}

Esta seção apresenta as produções científicas provenientes deste trabalho, bem como colaborações que este discente teve com outros trabalhos correlacionados durante o seu mestrado.

\section{Periódico}

- Qualis A2, Fator de Impacto 1.953

1. Filho, G.P.R.; Ueyama, J.; Villas, L.; Pinto A.R.; Vinícius P. Gonçalves; Gustavo Pessin; Richard W. Pazzi; Torsten Braun. "NodePM: A Remote Monitoring Alert System for Energy Consumption Using Probabilistic Techniques". Sensors 2014, v. 14, p. 848-867.

\section{Conferências}

- Qualis B2

1. Filho, G.P.R.; Ueyama, J.; Villas, L.; Pinto A.R.; Seraphini, A.P.S. “NodePM: Um Sistema de Monitoramento Remoto do Consumo de Energia Eletrica via Redes de Sensores sem Fio". XXXI Simpósio Brasileiro de Redes de Computadores e Sistemas Distribuídos, SBRC 2013.

2. Filho, G.P.R.; Ueyama, J.; Villas, L.; Pinto A.R.; Goncalves, V.P.; Seraphini, A.P.S. "An intelligent approach for improving energy efficiently in smart grids". Accept to publish in the 12th International Conference on Wireless Networks, ICWN 2013.

3. Goncalves, V.P; Neris, V.P.A.; Ueyama, J.; Seraphini, A.P.S.; Dias, T.C.M.; Filho, G.P.R.. "Senior Citizens in Interaction with Mobile Phones: A Flexible Middleware Approach to Support the Diversity". Accept to publish in the 13th International Conference on Software Engineering Research Practice, SERP 2013. 
- Qualis B3

1. Goncalves, V.P; Neris, V.P.A.; Ueyama, J.; Giancristofaro G.T; Filho, G.P.R.; Seraphini, A.P.S. "Emoções na Interação Humano-Computador: Um Estudo Considerando Sensores". XII Simpósio de Fatores Humanos em Sistemas Computacionais, IHC 2013.

\subsection{Trabalhos futuros}

Nesta seção, são apresentados possíveis propostas para a continuação deste trabalho, visto que várias ideias foram surgindo durante o mestrado. No entanto, tais propostas não foram desenvolvidas devido ao tempo e/ou por estarem fora do escopo.

- Desenvolver um método híbrido que mude em tempo de interação qualquer algoritmo de detecção de novidades de acordo com o ambiente monitorado.

- Analisar o impacto das transmissões realizadas entre os sensores e o gateway, pois as mensagens de cada sensor são enviadas a cada 5 segundos. Isto é, cerca de $17 \mathrm{mil}$ transmissões por dia.

- Propor modelos de privacidade baseado em Cavoukian et al. (2010), uma vez que as smart grids revelam informações detalhadas do dia-a-dia do usuário (revisite a Figura 4.6).

- Propor algoritmos para reduzir o consumo de energia baseado em tarifação em blocos. Isto é, tarifas diferenciadas por horário de consumo, como acontece na conta de telefone. 



\section{Referências Bibliográficas}

Akyildiz, I. F. e Vuran, M. C. (2010). Wireless Sensor Networks. John Wiley \& Sons Ltd. (Citado na página 5, 6, 6, 8, 9,9)

Akyildiz, L. F., Su, W., Sankarasubramaniam, Y., e Cayirci, E. (2002). A survey on sensor networks. (Citado na página 5, 7,7)

Albertini, M. K. e Mello, R. F. (2007). A self-organizing neural network for detecting novelties. In Proceedings of the 2007 ACM symposium on Applied computing. (Citado na página 32)

AlertMe (2012). Energy monitor save energy \& lower electricity costs alerme. http://www.alertme.com. visitado em 13 de Março de 2012. (Citado na página 1, $2,2,6,18,19)$

Basha, E. A., Ravela, S., e Rus, D. (2008). Model-based monitoring for early warning flood detection. In Proceedings of the 6th ACM conference on Embedded network sensor systems, SenSys '08, pp. 295-308, New York, NY, USA. ACM. (Citado na página 6)

Botte, B., Cannatelli, V., e Rogai, S. (2005). The telegestore project in enel's metering system. International Conference on Electricity Distribution, 18th. (Citado na página 2, 2, $17,18,18)$

Campus-Metabolism (2012). Arizona state university, (asu). http:/ / cm.asu.edu/\#app=4c 23\&6741-selectedIndex=1. visitado em 05 de julho de 2012. (Citado na página 2, 2, $18,18)$

Casimir, R., Boutleux, E., Clerc, G., e Yahoui, A. (2006). The use of features selection and nearest neighbors rule for faults diagnostic in induction motors. Eng. Appl. Artif. Intell., 19(2):169-177. (Citado na página 13)

Cavoukian, A., Polonetsky, J., e Wolf, C. (2010). Smartprivacy for the smart grid: embedding privacy into the design of electricity conservation. Identity in the Information Society, 3(2):275-294. (Citado na página 45) 
CIB (2013). Ampla cidade inteligente búzios (cib) - energia para um mundo melhor. http://www.cidadeinteligentebuzios.com.br/. visitado em 17 de setembro de 2013. (Citado na página 2, 18,20)

Correa, U., Pinto, A., Codas, A., Ferreira, D., e Montez, C. (2006). Redes locais sem fio: Conceitos e aplicacoes. IV Escola Regional de Redes de Computadores. Passo Fundo, Brasil. (Citado na página 9)

Cover, T. e Hart, P. (1967). Nearest neighbor pattern classification. IEEE Transactions on Information Theory, 13(1):21-27. (Citado na página 13,14)

DATA, P. (2013). World development indicators. http:/ / www.google.com/publicdata/ex plore?ds=d5bncppjof8f9_. visitado em 26 de agosto de 2013. (Citado na página 1)

Duarte, L. F. C., Zambiaco, J. D., Airoldi, D., Ferreira, E. C., e Dias, J. A. S. (2011). Characterization and breakdown of the electricity bill using custom smart meters: a tool for energy-efficiency programs. International journal of circuits, system and signal processing. (Citado na página 2, 2, 9, 17, 18,19)

ENERGY (2012). Smart grid I department of energy. http:/ / energy.gov/oe/technologydevelopment/smart-grid. visitado em 05 de março de 2012. (Citado na página 1,6)

Erol-Kantarci, M. e Mouftah, H. (2011). Wireless sensor networks for smart grid applications. In Electronics, Communications and Photonics Conference (SIECPC). (Citado na página $2,6,8,8,11$ )

Erol-Kantarci, M. e Mouftah, H. T. (2010). Wireless sensor networks for domestic energy management in smart grids. Biennial Symposium on Communications, 25th. (Citado na página $1,2,17,18,18)$

Ester, P. (1985). Consumer behavior and energy conservation : a policy-oriented experimental field study on the effectiveness of behavioral interventions promoting residential energy conservation / by peter ester. (Citado na página 2)

Falcão, D. M. (2009). Smart grids e microredes: O futuro jÁ É presente. VII Simpósio de Automação de Sistemas Elétricos (SIMPASE). (Citado na página 10,11,11)

Fawcett, T. (2006). An introduction to roc analysis. Pattern recognition letters, 27(8):861 874. (Citado na página 36)

Feisst, C., Schlesinger, D., e Frye, W. (2008). Smart grid, the role of electricity infrastructure in reducing greenhouse gas emissions. Cisco Internet Business Solution Group (IBSG). (Citado na página 1 ) 
Filho, G. P. R., Ueyama, J., Villas, L., Pintoand, A., Gonçalves, V. P., e Seraphini, S. (2013). An intelligent approach for improving energy efficiently in smart grids. In International Conference on Wireless Networks (ICWN), v. 12, pp. 227-233. (Citado na página 9)

Filho, G. P. R., Ueyama, J., Villas, L., Pintoand, A., e Seraphini, S. (2013). Nodepm: Um sistema de monitoramento remoto do consumo de energiaelétrica via redes de sensores sem fio. In sociedade Brasileira de Computação (SBC), editor, Simpósio Brasileiro de Redes de Computadores e Sistemas Distribuídos (SBRC), v. 31, pp. 17-30. (Citado na página 8)

Filho, G. P. R., Ueyama, J., Villas, L. A., Pinto, A. R., Gonçalves, V. P., Pessin, G., Pazzi, R. W., e Braun, T. (2014). Nodepm: A remote monitoring alert system for energy consumption using probabilistic techniques. Sensors, 14(1):848-867. (Citado na página 6)

Freeman, J. A. e Skapura, D. M. (1991). Neural networks: Algorithms, applications, and programming techniques (computation and neural systems series). Neural networks: algorithms, applications and programming techniques (Computation and Neural Systems Series). (Citado na página 16)

Gungor, V. C., Lu, B., e Hancke, G. P. (2010). Opportunities and challenges of wireless sensor networks in smart grid. Industrial Electronics, IEEE Transactions on, 57(10):35573564. (Citado na página 10,11,11)

Hughes, D., Ueyama, J., Mendiondo, E., Matthys, N., Horre, W., Michiels, S., Huygens, Christopheand Joosen, W., Man, K., e Guan, S.-U. (2011). A middleware platform to support river monitoring using wirelesssensor networks. Journal of the Brazilian Computer Society, 17(2):85-102. (Citado na página 6, 7,9)

Jain, R. (1991). The art of computer systems performance analysis: Techniques for experimental design, measurement, simulation, and modeling. SIGMETRICS Perform. (Citado na página 31,37)

Jota, F. G., Jota, P. R. S., e Nobre, E. C. (2006). Gerenciamento efetivo de energia por uso final: Um sistema de monitoramento de baixo custo via internet. Seminário Nacional de Distribuição de Energia Elétrica, XVII. (Citado na página 2, 2, 17, 18,19)

Juang, P., Oki, H., Wang, Y., Martonosi, M., Peh, L. S., e Rubenstein, D. (2002). Energyefficient computing for wildlife tracking: design tradeoffs and early experiences with zebranet. SIGOPS Oper. Syst. Rev., 36(5):96-107. (Citado na página 6, 6, 7,10)

Kim, Y., Schmid, T., Charbiwala, Z. M., Friedman, J., e Srivastava, M. B. (2008). Nawms: Nonintrusive autonomous water monitoring system. (Citado na página $6,8,8$ ) 
Larose, D. T. (2005). Discovering knowledge in data: an introduction to data mining. Wiley. com. (Citado na página 14,14)

Light, S. G. (2012). Conceitos smart grid. http:/ / smartgridlight.com.br/conceitos-smartgrid/. (Citado na página 10)

Lorincz, K., Welsh, M., Marcillo, O., Johnson, J., Ruiz, M., e Lees, J. (2006). Deploying a wireless sensor network on an active volcano. In IEEE Internet Computing, pp. 18-25. (Citado na página 6,7)

Loureiro, A. A., Nogueira, J. M. S., Ruiz, L. B., de Freitas Mini, R. A., Nakamura, E. F., e Figueiredo, C. M. S. (2003). Redes de sensores sem fio. Simpósio Brasileiro de Redes de Computadores, SBRC, 21ํ:179-116. (Citado na página 5, 6,9)

MAGGI, B. (2012). Projeto de lei no 84/2012. http:/ / www.senado.gov.br/atividade/mat eria/-getPDF.asp?t=105231\&tp=1. (Citado na página 1, 2, 17,18)

Malan, D., Fulford-jones, T., Welsh, M., e Moulton, S. (2004). Codeblue: An ad hoc sensor network infrastructure for emergency medical care. In In International Workshop on Wearable and Implantable Body Sensor Networks. (Citado na página 7,7,9)

Markov, A. A. (1971). Extension of the limit theorems of probability theorty to a sum of variables connected in a chain. pp. 552-577. (Citado na página 15, 15,28)

Marsland, S., Shapiro, J., e Nehmzow, U. (2002). A self-organising network that grows when required. Neural Netw., 15(8):1041-1058. (Citado na página 32)

Mcmakin, A. H., Malone, E. L., e Lundgren, R. E. (2002). Motivating residents to conserve energy without financial incentives abstract:. (Citado na página 2)

Mitchell, T. M. (1997). Machine Learning. McGraw-Hill Science. (Citado na página 12, 13,32)

Munroe, D. T. e Madden, M. G. (2005). Multi-class and single-class classification approaches to vehicle model recognition from images. In AICS, number 16th, pp. 93102. Irish conference on artificial intelligence and cognitive science (AICS). (Citado na página 13)

Power-Meter (2012). Google powermeter: A google.org project. http: / / www.google.com/powermeter. visitado em 14 de Março de 2012. (Citado na página $2,2,17$ )

Pratap, K. e Shelja (2013). Artificial neural network (ann) inspired from biological nervous system. International Journal of Application or Innovation in Engineering \& Management (IJAIEM), pp. 227-231. (Citado na página 12) 
Prathap, U., Shenoy, P. D., Venugopal, K., e Patnaik, L. (2012). Wireless sensor networks applications and routing protocols: Survey and research challenges. In Cloud and Services Computing (ISCOS), 2012 International Symposium on, pp. 49-56. IEEE. (Citado na página 5)

Rocha, J. W. V. (2007). Seção: Tutoriais redes opticas. visitado em 05 de setembro de 2012. (Citado na página 6, 9,9)

Ross, S. M. (1997). Introduction to probability models, v. 6. Academic Press San Diego, California. (Citado na página 15, 15,15)

SGL (2013). Smart grid light - energia inteligentes. http://smartgridlight.com.br/. visitado em 17 de setembro de 2013. (Citado na página 2, 18,20)

Shannon, C. (1948). A Mathematical Theory of Communication. The Bell System Technical Journal. (Citado na página 16)

Sibbald, B. (2001). Use computerized systems to cut adverse drug events: report. Canadian Medical Association Journal (CMAJ). (Citado na página 6, 6, 7,7)

Siddiqui (2008). T he green grid: Energy savings and carbon emissions reductions enabled by a smart grid. EPRI Technical Update Report 1016905. (Citado na página 10)

Sioshansi, F. P. (2012). Smart Grid: Integrating Renewable, Distributed E Efficient Energy. Elsevier. (Citado na página 10)

Spinosa, E. J. (2008). Detecção de novidade com aplicação a fluxos contínuos de dados. PhD thesis, Universidade de São Paulo - USP. (Citado na página 12,12)

Stern, P. C. (1999). Information, incentives, and proenvironmental consumer behavior. Journal of Consumer Policy, 22:461-478. (Citado na página 2)

Will, J., O'Connell, T., e Lange, C. (2009). Smart grid is a global priority. Smart Grid. https:/ / courses.cit.cornell.edu/crp384/2009reports/LangeOt (Citado na página 1)

Yang, Y. e Liu, X. (1999). A re-examination of text categorization methods. In Proceedings of the 22nd annual international ACM SIGIR conference on Research and development in information retrieval, pp. 42-49. ACM. (Citado na página 27) 
